Cultural Variability in Appraisal Patterns for Nine Positive Emotions

\author{
Yong-Qi Cong ${ }^{1}$, Dacher Keltner ${ }^{2}$ and Disa Sauter ${ }^{1}$ \\ ${ }^{1}$ University of Amsterdam \\ ${ }^{2}$ University of California, Berkeley
}




\begin{abstract}
Emotions result from evaluations of events, referred to as appraisals. Specific configurations of appraisals have been shown to characterize different emotions, with some variation occurring across cultures. However, appraisal research to date has focused primarily on negative emotions, though recent efforts have started to also examine the appraisal profiles of positive emotions. Cross-cultural work on the appraisals of positive emotions has, however, been scarce. Here, we examine the appraisal profiles of nine positive emotions in the US and China. Using 13 commonly employed appraisal dimensions, we investigated the evaluations of events eliciting amusement, awe, compassion, desire, gratitude, interest, love, pride, and relief. Eighty participants from China and the US recalled events from their own life involving each of these emotions and provided Likert-scale appraisal ratings for each emotional event. Consistent with previous research, we find distinct appraisal patters for each positive emotion. We also, for the first time, demonstrate cultural variations in appraisals of positive emotions. Our study extends existing research by highlighting differences in appraisals of positive emotions across cultures.
\end{abstract}

Keywords: positive emotions, appraisals, culture 


\section{Cultural Variability in Appraisal Patterns for Nine Positive Emotions}

The vast majority of research on emotions focuses on negative affective states. For example, the well-known set of "basic emotions" (Ekman, 1992) includes several negative states like anger, disgust, fear and sadness, but only one category of positive emotion: happiness. This emphasis on negative emotions is partly due to the fact that pleasant experiences are thought to be less differentiated than unpleasant experiences (e.g., de Rivera et al., 1989; Ekman, 1992). However, in recent years, researchers are increasingly studying positive emotions and making distinctions between different positive emotional states (Campos et al., 2013; Fang, 2020; Graham et al., 2017; Sauter, 2017; Shiota et al., 2017; Weidman \& Tracy, 2020). This work has yielded support for distinct categories of positive emotions in terms of several emotion components, including subjective experience and nonverbal expressions (e.g., Cordaro et al., 2018; Laukka et al., 2013; Shiota et al., 2011).

A key component of emotions is appraisals, that is, an individual's subjective evaluation of an emotion-eliciting event or situation (Moors et al., 2013; Scherer, 1999). Several studies have empirically demonstrated that positive emotions can be differentiated based on their appraisal patterns. For example, Ellsworth and Smith (1988) studied pleasant emotional experiences in terms of participants' appraisals of effort, agency, and certainty. The appraisal patterns of six positive emotions (interest, hope, challenge, tranquility, playfulness, and love) showed considerable differentiation. A recent study replicated these findings and identified distinct appraisal profiles for the additional positive emotions of amusement, awe, compassion, gratitude, joy, interest, pride and relief (Yih et al., 2020). The current study aims to extend this research by examining the appraisals of positive emotions across cultures.

\section{Emotion Appraisals across Cultures}

Culture guides an individual's construction of meaning (Hong et al., 2000; Kitayama et al., 2010; Kitayama \& Park, 2010), and has been shown to shape individuals' expressions 
and experiences of emotions (e.g., Boiger et al., 2014; Elfenbein, 2007; Laukka et al., 2016; Kawahara et al., 2021; Yuki et al., 2007). Given the highly subjective nature of evaluations of events and situations, one might expect significant cultural differences in appraisals (Mesquita \& Ellsworth, 2001; Mesquita \& Frijda, 1992). Indeed, several studies have shown that emotional appraisals for the same emotions differ across cultures. Mauro and colleagues (1992) studied the appraisal patterns of 14 emotions in China, Japan and the US. Their analyses were conducted only at the level of appraisal dimensions, not specific emotions. Their results revealed substantial cultural differences in evaluations on multiple appraisal dimensions, including control, responsibility, and anticipated effort. Another study (Roseman et al., 1995 ) investigated the appraisal patterns of anger, fear, and sadness in India and the US. Significant cultural differences were observed, with Indian participants perceiving greater causation by circumstances in anger-eliciting situations. Indian participants also evaluated all three types of emotional situations to be more consistent with their motives and more uncertain, and they perceived themselves to have less power in those situations.

In a large-scale cross-cultural study, Scherer (1997) investigated the appraisals of seven emotions (joy, anger, fear, sadness, disgust, shame, and guilt) across 37 countries. Considerable cultural differences were observed in general appraisal tendencies. For example, participants from Latin America judged events to be low on immorality for all emotions except joy. Moreover, participants from Africa rated all emotions except joy as more unfair and more externally caused compared to participants from other regions. These studies demonstrate cultural variations in appraisal patterns. However, the emotions examined in these studies were largely negative.

In contrast, cross-cultural research on the appraisals of positive emotion is scarce, with only one study conducted to date. Tong (2015) studied the appraisal patterns of 13 positive emotions (amusement, awe, challenge, compassion, contentment, gratitude, hope, 
interest, joy, pride, relief, romantic love, and serenity) in the US and Singapore. Participants recalled and described situations in which they experienced each of the emotions and rated their experience on 13 appraisal dimensions (pleasantness, relevance, problem, goal-attainment, agency-self, agency-other, agency-circumstances, control-self, control-other, controlcircumstances, certainty, predictability, and effort). The results showed no significant cultural differences in the appraisal patterns between the two cultures, in contrast with research on negative emotions that has found considerable cultural variation (e.g., Borke \& Su, 1972; Matsumoto et al., 1988; Mauro et al., 1992; Scherer, 1997; Scherer \& Wallbott, 1994).

One potential reason for the lack of cultural differences in Tong's (2015) study could be the cultural distance between the two sample cultures. Singapore is a westernized, metropolitan society, with a highly capitalistic economy (Sim, 2001; Sklair, 2001; Wee, 2000). English is spoken as the lingua franca in Singapore, and perhaps because of the access to English-language media, Singaporean cultural values are heavily influenced by the west (Valsh, 2007; Yeoh, 2004). These similarities between Singapore and the US may explain the similar patterns in emotion experiences found by Tong (2015).

The current study aims to investigate whether appraisals of positive emotions are similar across cultures by comparing two populations that are culturally more different: the US and China. We examined nine positive emotions (amusement, awe, compassion, desire, gratitude, interest, love, pride, and relief). We sought to investigate emotions that have previously been shown to have distinct appraisal patterns (Ellsworth \& Smith, 1988; Tong, 2015; Yih et al., 2019), since the focus of our study was on the cultural variability of these patterns. Additionally, we only included emotions that have previously been shown to be associated with some expressive behaviors, as this is an important point of consideration in the discussion of universality and cultural specificity of emotions (Campos et al., 2013; Mortillaro et al., 2011; 
Sauter, 2017; Shiota et al., 2003). Below, we review the existing literature on the appraisal patterns of these nine emotions.

\section{Amusement}

Amusement is typically elicited by benign events that violate expectations (McGraw \& Warren, 2010; Morreall, 1989). It has been theorized that amusement has the adaptive function of learning and developing flexible cognition through playful behavior (Campos et al., 2013; Shiota et al., 2014). Appraisal research on amusement has shown that events eliciting amusement are associated with high ratings of pleasantness and agency of others, and low ratings of problems, agency of oneself and agency of the circumstances (Tong, 2015; Scherer \& Ceshi, 1997).

\section{Awe}

Awe is a self-transcendent emotion that is typically elicited by perceptually complex and information-rich external stimuli that are not social (Keltner \& Haidt, 2003; Shiota et al., 2007). Awe motivates knowledge seeking (Chirico \& Yaden, 2018; Shiota et al., 2014; Steller et al., 2017), and inspires individuals to revise or update their understanding of the aweevoking object (Keltner \& Haidt, 2003). When experiencing awe, individuals have been shown to feel small and insignificant, and as if they are a small part of something larger (Bai et al., 2017; Campos et al., 2013; Shiota et al., 2017). Awe has also been shown to be associated with the feeling that a situation challenges one's worldview (Keltner \& Haidt, 2003; Shiota et al., 2007). Previous research on the appraisal patterns of awe has found that events eliciting awe are evaluated as pleasant and externally caused (Tong, 2015; Yih et al., 2020).

\section{Compassion}

Compassion is generally experienced in reaction to someone suffering a misfortune that they did not create and that cannot be controlled (Goetz et al., 2010). The experience of compassion is thus related to high levels of external causation and is perceived as involving a 
problem (Tong, 2015). Compassion has been shown to motivate actions to change the situation so that the victim can be alleviated from the misfortune (Goetz et al., 2010; Stellar et al., 2017). Compassion is associated with situations that are inconsistent with one's wishes and that evoke low levels of personal control, suggesting that compassion is linked to a sense of helplessness (Tong, 2015). Although compassion is often studied as a positive emotion, it is not always experienced as pleasant (Smith et al., 2014; Tong, 2015). Compassion has been evaluated as high on problems, low on pleasantness, and high on external causation and external control.

\section{Desire}

Very little empirical work has been done to examine the appraisal patterns of desire (though see Gonzaga et al., 2006 on romantic love and sexual desire). Desire is sometimes used interchangeably with "wanting" in philosophy and neuroscience, often studied as a process that motivates the pursuit of rewards (Berridge, 2009; Robinson et al., 2015; Schroeder, 2006). Desire is thus associated with pursuing pleasure (Schoeder, 2006) and is often elicited by salient incentives (Berridge, 2009). To our knowledge, no previous research has studied the appraisal patterns of desire.

\section{Gratitude}

We often feel grateful when benefiting from the kind actions of someone else (McCullough et al., 2001). Gratitude is characterized by both benefitting from another person, and the desire to give back (Campos et al., 2013). In fact, gratitude has been shown to motivate not only reciprocal responses to the benefactor, but also prosocial behaviors towards others (Algoe et al., 2008; Bartlett \& DeSteno, 2006; McCullough et al., 2001). In line with these, appraisal studies have found gratitude to be associated with high ratings of pleasantness, goal-attainment, relevance, and agency of others (Reisenzein \& Spielhofer, 1994; Tong, 2015). 


\section{Interest}

Interest is theorized to be a knowledge-based emotion whose theme is exploration, discovery and learning (Ellsworth \& Smith, 1988; Silvia, 2008; Sung \& Yih, 2015). Theories of interest conceptualize it as combining novelty-complexity and coping potential (Silvia, 2008), meaning that people are curious to explore novel and complex things to the extent that they can understand them. Indeed, interest has been shown to be associated with high levels of pleasantness, relevance and personal control (Tong, 2015; Yih et al., 2020).

\section{Love}

Love has been defined as an emotion experienced during closeness or reunion with an attachment figure, serving the function of social bonding (Bowlby, 1979; Shiota et al., 2004, 2007). It has been theorized that love motivates moving closer to another in social space, seeking connectedness and supporting relationships (Campos et al., 2013; Roseman, 2013; Shiota et al., 2014; Smith et al., 2014). It has also been argued that feeling vulnerable to another is an important element of love (Campos et al., 2013; Fischer \& Ayoub, 2013). Love has been shown to be associated with high levels of pleasantness and agency of others (Tong, 2015).

Pride

Pride is often elicited by personal or collective accomplishment and involves status advancements and positive self-perception (Campos et al., 2013; Tracy \& Robins, 2004; William \& Desteno, 2009). It has been theorized that pride serves adaptive functions as it advertises achievements that are socially valued and thereby aids one's advancement within a hierarchical social structure (Shiota et al., 2014; Tracy \& Robins, 2007; William \& Desteno, 2009). Pride motivates behaviors to attain further dominance and prestige (Roseman, 2013; Tracy et al., 2010; see Henrich \& Gil-White, 2001, for the dominance-prestige theory) and is associated with positive evaluation by others (Tong, 2015; Tong \& Jia, 2017; Yih et al., 
2020). Previous research on the appraisal pattern of pride has shown that pride is associated with high pleasantness, self-accountability, relevance and goal-attainment (Tong, 2015; Tong \& Jia, 2017; Yih et al., 2020).

\section{Relief}

Relief is experienced when an undesired outcome is avoided (Roseman et al., 1990; Roseman, 1996, 2013). Research on the appraisals associated with relief is thin, but there is evidence that situations eliciting relief are perceived as involving problems that need to be solved and that it is associated with attaining one's goals or wishes (Tong, 2015; Yih et al., 2020). This suggests that relief is experienced when problems are resolved in accordance with one's goal. Relief has also been shown to be associated with high pleasantness and other-accountability (Tong, 2015; Tong \& Jia, 2017).

\section{The Current Study}

The overarching goal of the present study was to investigate the appraisal patterns of nine positive emotions. We sought to extend the existing literature by examining appraisals of positive emotions cross-culturally. Participants from China and the US recalled autobiographical events associated with nine emotions (amusement, awe, compassion, desire, gratitude, interest, love, pride, and relief) and reported their appraisals of the recalled events. Based on previous research, we expected to find differentiable appraisal patterns across the nine emotions. We also expected to find cultural variations on at least some of the appraisal items. However, we do not have hypotheses on the specific appraisal dimensions that would show cultural variations.

\section{Method}

\section{Participants}


The sample consisted of 50 Chinese adults between the ages of 19 and 52 years old (38 women and 12 men, $\mathrm{M}_{\mathrm{age}}=25.6, \mathrm{SD}_{\mathrm{age}}=7.6$ ) from Dalian, a city in the Northeast of China, and 30 American adults between the ages of 20 and 67 years old (17 women and 13 men, $\left.\mathrm{M}_{\mathrm{age}}=33.7, \mathrm{SD}_{\mathrm{age}}=14.1\right)$ from Berkeley, a city on the west coast of the US. Participants from both cultures were community members recruited locally through announcements on social media. None of the participants had lived for more than one year outside of their home country. All participants received monetary compensation for taking part in the study.

\section{Design and Procedure}

For each emotion, participants recalled a specific time in their life when they had experienced the target emotion. Participants talked about their experience to an experimenter while being video recorded. The video recordings were later used in investigating research questions relating to expressive behaviors of these emotions, which are not discussed in this paper. The bilingual experimenter (author Y.C.) was consistent across all participants in both cultures. After recalling every event, participants answered questions on their emotional experience and appraisals of the event (see Materials). We used a fully within-subject design and so all participants completed all appraisal questions for all emotions ${ }^{1}$. The order of emotions was randomized across participants and the order of questions was the same for all participants.

Participants listened to a recording of the name and definition of a target emotion in their own language. They were then asked to explain the emotion in their own words to make sure that they understood the emotion. If the experimenter judged a participant to have misunderstood the target emotion, the experimenter played the recording of the emotion definition again and explained the emotion in other words to the participants until they understood

\footnotetext{
${ }^{1}$ Five participants did not finish all the emotions within the scheduled time. Each of these participants missed one emotion condition ( $1 x$ amusement, $1 x$ love, $1 x$ interest, $2 x$ desire). The eight emotions that each of these participants did complete were included in the data.
} 
(Sauter et al., 2015). Participants were then asked to recall a specific event involving the emotion and to talk about it in detail. Participants were not restricted in the amount of time they had to talk about each emotional event. After recalling the event for one emotion, participants filled in the appraisal questionnaires before moving on to the next emotion. The procedure was repeated for all nine emotions or until two hours elapsed since the start of the session. ${ }^{2}$ The same procedure was followed in both countries.

\section{Materials}

\section{Emotion Experience}

Participants rated the extent to which they had experienced the target emotion during the event (How strongly did you experience this emotion during the event?) as well as during the recall of the event (How strongly did you experience this emotion while recalling the event? $)$. Emotion intensity was rated on a scale of 0 to $10(0=$ Not at all, $10=$ Extremely $)$. This measure was included to check that participants indeed experienced the target emotion in each emotion condition.

\section{Appraisal Questionnaire}

The appraisal questionnaire included 13 appraisal dimensions, following Tong (2015). These were: Pleasantness, Relevance, Problem, Goal attainment, Agency-self, Agency-other, Agency-circumstances, Control-self, Control-other, Control-circumstances, Certainty, Predictability, and Effort. All items were rated on a 0 to 10 Likert-scale $(0=$ Not at all, $10=E x$ tremely). An NA (not applicable) option was also included for each item, to be selected if participants thought the feature was not relevant for their experience. The questionnaires were translated from English into Chinese by bilingual research assistants in Berkeley with

\footnotetext{
${ }^{2}$ The original procedure also included a 10th emotion, embarrassment. Because embarrassment is not a positive emotion, it is not reported within the present paper. Participants also filled in an additional questionnaire in relation to different research questions after completing the measures reported here. Those data are not discussed further. Finally, participants also posed emotional expressions at the end of the experimental session. This related to our investigation of the expressive behaviors of these emotions and is therefore also not reported in the present manuscript.
} 
previous experience in translating research materials between the two languages. The complete list of questions can be found in the Supplementary Materials.

\section{Results}

\section{Emotion Intensity}

To examine the extent to which participants experienced the target emotion at both the time of the event and the recall, a 9 (emotion) x 2 (time: past and present) x 2 (culture) mixed analysis of variance (ANOVA) was performed with emotion and time as within-subject factors and culture as a between-subject factor. Overall, participants experienced rather high levels of all the emotions both during the actual events and during recall. However, the emotion intensity was on average higher in the past $(M=8.60, S D=1.73)$ than at present $(M$ $=6.86, S D=2.48)$, as evidenced by a significant main effect of time, $F(1,74)=148.01, p<$ $0.001, \eta^{2}=0.14$. There was also a significant main effect of emotion, $F(8,592)=3.39, p<$ $0.001, \eta^{2}=0.02$, indicating that the emotions were experienced to different levels of intensity. There was no significant main effect of culture, but a significant interaction effect between culture and emotion, $F(8,592)=2.25, p=0.02, \eta^{2}=0.01$. Additionally, there was an interaction effect between emotion and time, $F(6.37,471.29)=2.53, p=0.02, \eta^{2}=0.01$. These results are illustrated in Figure 1.

\section{Figure 1}

Self-reported Emotional Intensity (scale 0-10) in the Past (During Event; solid line) and at Present (During Recall; dotted line) for nine emotions in both cultures. Points indicate means and error bars indicated standard deviations. 

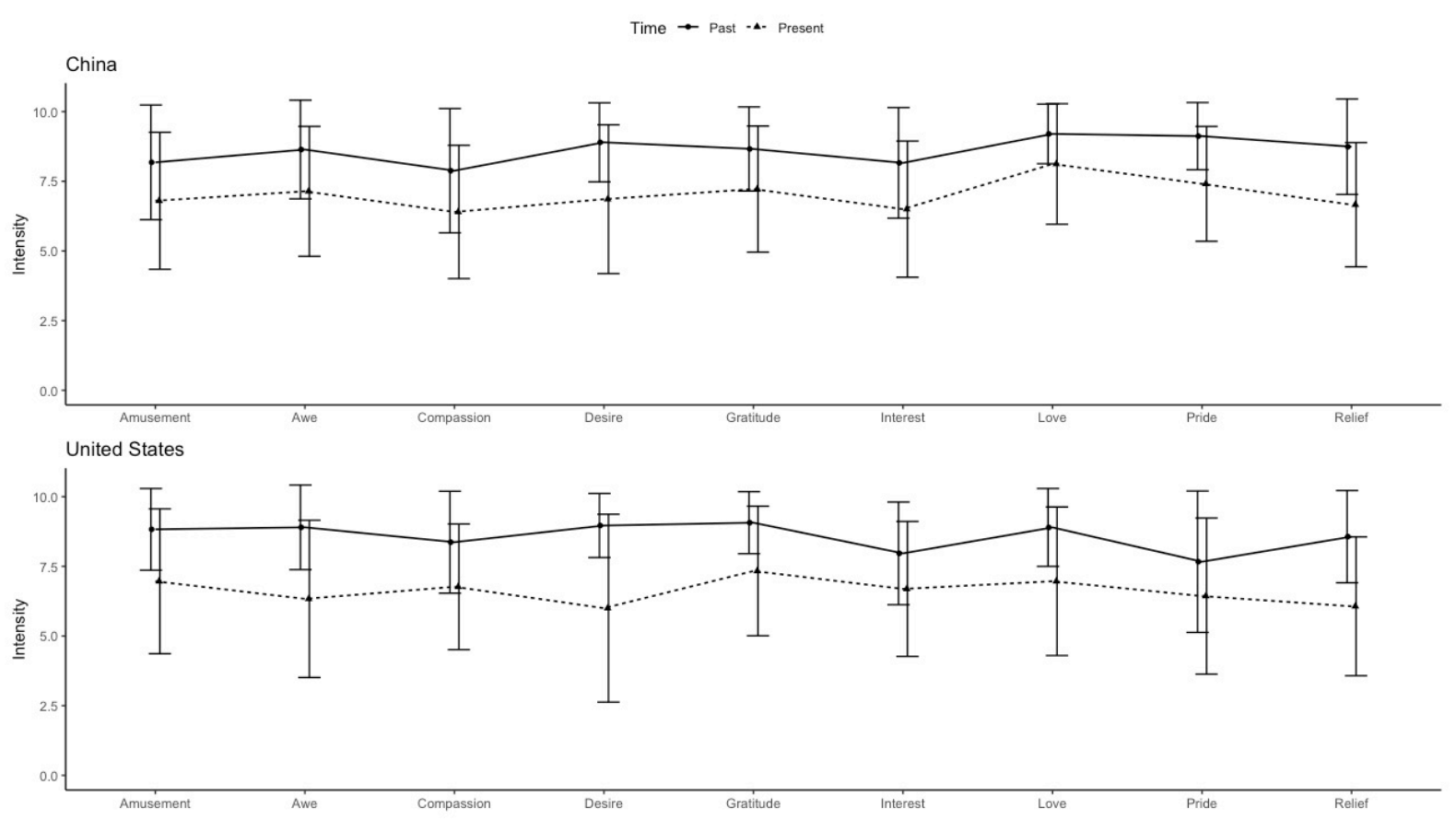

\section{NA Responses and Data Processing}

For all appraisal items, an NA (not applicable) option was provided so that participants would have the possibility to skip an appraisal item if they did not consider this feature to be applicable or relevant to the event. There was a total of 9,360 possible appraisal data points (13 appraisal items $x 9$ emotions $x 80$ participants). Excluding the 65 data points missing from the five participants that did not complete all emotion conditions (13 appraisals $x 5$ emotions) yielded a total of 9,295 data points.

Participants made use of the NA option 614 times in total, which was $6.6 \%$ of all answers. This is somewhat lower than the average of $16.3 \%$ reported by Scherer (1997) and $10.01 \%$ reported by Tong (2015). To examine whether participants from the two cultures differed in how frequently they made use of the NA option, a Fischer exact probability test was performed. The proportion of NA responses was significantly different between the two cultures, $X^{2}(1, N=9,295)=177.45, p<0.001$, with Chinese participants making use of the NA options more often $(9.25 \%)$ than the US participants did $(2.12 \%)$.

In order to preserve maximum statistical power, all subsequent analyses were performed with the NA responses re-coded as 0 . A consistent pattern of results was found when 
NA responses were coded as missing data; These additional analyses can be found in the Results section in the supplementary materials.

\section{Discriminant Power of the Appraisals}

To investigate the extent to which the nine emotions could be differentiated based on their appraisal profiles, we within-subject standardized the data and conducted discriminant analyses separately for the two cultural groups. Specifically, we were interested in finding out whether the emotion categories could be correctly classified using the appraisal items as predictors. We compared the classification rate of appraisal items with chance level set to 1/9.

For the Chinese data, using all 13 appraisal items as predictors for the nine emotions, $39.78 \%$ of all cases were correctly classified; the leave-one-out classification rate was $34.00 \%$. For data from the US, we were able to correctly classify $42.59 \%$ of all emotion cases; the leave-one-out classification rate was $38.15 \%$. These classification rates were similar to those reported by Tong $(2015 ; 42.4 \%$, and $36.4 \%$ for leave-one-out). Classification rates for each emotion are reported in Table 1.

Most emotions were correctly classified at rates considerably higher than the overall chance classification rate (i.e., prior probability). Exceptions were love and interest, which both had lower classification rates than the other emotions. The classification rates of interest were only slightly higher than chance in both cultures. In the case of love, the classification rates in the US data were considerably higher than those in the Chinese data, and the leaveone-out classification rate was not above chance accuracy for the Chinese data.

\section{Table 1}

Classification rates of 9 positive emotions by appraisal.

\begin{tabular}{ccccccc}
\hline \multirow{2}{*}{ Emotion } & \multicolumn{3}{c}{ China } & & \multicolumn{2}{c}{ US } \\
\cline { 2 - 7 } & Prior & Original & Leave one out & prior & Original & Leave one out \\
\hline Amusement & $11.11 \%$ & $54.00 \%$ & $46.00 \%$ & $10.90 \%$ & $65.52 \%$ & $65.52 \%$ \\
\hline Awe & $11.11 \%$ & $34.00 \%$ & $30.00 \%$ & $11.28 \%$ & $46.67 \%$ & $43.33 \%$
\end{tabular}




\begin{tabular}{ccccccc}
\hline Compassion & $11.11 \%$ & $90.00 \%$ & $88.00 \%$ & $11.28 \%$ & $63.33 \%$ & $60.00 \%$ \\
\hline Desire & $10.91 \%$ & $38.78 \%$ & $32.65 \%$ & $10.90 \%$ & $48.28 \%$ & $41.38 \%$ \\
\hline Gratitude & $11.11 \%$ & $38.00 \%$ & $28.00 \%$ & $11.28 \%$ & $46.67 \%$ & $36.67 \%$ \\
\hline Interest & $11.11 \%$ & $18.00 \%$ & $12.00 \%$ & $10.90 \%$ & $10.34 \%$ & $13.79 \%$ \\
\hline Love & $11.11 \%$ & $12.00 \%$ & $4.00 \%$ & $10.90 \%$ & $27.59 \%$ & $20.69 \%$ \\
\hline Pride & $11.11 \%$ & $46.00 \%$ & $38.00 \%$ & $11.28 \%$ & $46.67 \%$ & $40.00 \%$ \\
\hline Relief & $11.11 \%$ & $28.00 \%$ & $28.00 \%$ & $11.28 \%$ & $33.33 \%$ & $26.67 \%$ \\
\hline
\end{tabular}

\section{Appraisal Patterns and Cultural Variability}

Before analyzing the appraisal patterns, we first compare the two samples in terms of demographics. First, we conducted a chi-squared test comparing the proportion of men versus women in the two samples. There was no significant difference between the proportion of women in the Chinese sample $(78.00 \%)$ versus the US sample $(56.67 \%), \mathrm{X}^{2}(1, N=80)=$ $3.11, p=0.08$. Since we did not hypothesize any effect of gender, we did not include this factor in the analyses.

Next, we compared the two samples on the age of the participants. An independentsample t-test revealed a significant difference in mean age between the two samples, $t(4753.56)=-32.05, p<0.001$, with the participants from China $(M=25.6, \mathrm{SD}=7.5)$ being younger than participants from the US $(M=33.7, S D=13.9)$ on average. We subsequently included age as a covariate in the following analyses.

To examine whether the appraisal profiles would differ across emotions and between the two cultures, we performed a 9 (emotion) x 13 (appraisal items) x 2 (culture) mixed analysis of variance (ANOVA) with culture as a between-subject factor, emotion and appraisal item as a within-subject factors, appraisal ratings as the dependent variable, and age as a covariate. There was a significant main effect of emotion, $F(8,592)=4.43, p<0.001, \eta^{2}=$ 0.01 , and a significant main effect of appraisal, $F(12,888)=6.99, p<0.001, \eta^{2}=0.02$. 
There were also significant interaction effects between appraisal and emotion $F(96,7104)=$ 3.03, $p<0.001, \eta^{2}=0.03$, and between appraisal and culture, $F(12,888)=3.33, p<0.001$, $\eta^{2}=0.01$. The interaction effects indicate that the appraisal profiles differ across emotions, and between the two cultures. There was also a significant three-way interaction effect between appraisal, emotion, and culture, $F(96,7104)=2.42, p<0.001, \eta^{2}=0.02$, implying that the differences in appraisal profiles across emotions are characterized differently in the two cultures. The covariate effect of age was not significant, $F(1,74)=0.007, p=0.94, \eta^{2}<$ 0.001 .

To better understand the interaction effects with culture and to profile the appraisal patterns of each emotion, we proceeded with conducting two-way ANOVAs for each of the 9 emotions separately with culture as a between-subject factor, appraisal items as within-subject factor, and age as a covariate. To correct for multiple comparisons, the significance level for p-values was Bonferroni corrected to 0.006, based on conducting nine ANOVAs (i.e., al$p h a=0.05 / 9)$. There was a significant main effect of appraisal on six of the nine emotions, namely amusement, awe, compassion, interest, pride and relief. This suggests that appraisal patterns differed across these emotions. There was a significant interaction effect between appraisal and culture for four emotions, namely awe, compassion, desire and gratitude. This indicates that for these emotions, the appraisal patterns differed between the two cultures. The statistics of these tests are reported in Table 2. The covariate effects of age were not significant for any of the emotion.

For all of the interaction effects that were significant in the previous step, we performed post hoc simple effects analyses to examine on which appraisal dimensions cultural differences would emerge. The significance level was Bonferroni corrected to 0.001 (4 emotions $\mathrm{x} 13$ appraisal items $=52$ tests, i.e., alpha $=0.05 / 52$ ). Below, we report the emotion specific appraisal patterns per emotion, as well as the results of the post hoc simple effects tests. 
Table 2

Statistics of Results for ANOVA Tests per Emotion, with Culture as a Between-Subject Factor and Appraisal Items as a Within-Subject Factor

\begin{tabular}{lccccccccc}
\multicolumn{1}{c}{ Emotion } & \multicolumn{3}{c}{ Appraisal } & \multicolumn{3}{c}{ Culture } & \multicolumn{3}{c}{ Appraisal x Culture } \\
\hline & $F$ & $p$ & $\eta^{2}$ & $F$ & $p$ & $\eta^{2}$ & $F$ & $P$ & $\eta^{2}$ \\
Amusement & 6.58 & $<\mathbf{0 . 0 0 1}$ & 0.067 & 0.05 & 0.83 & 0.0001 & 1.51 & 0.16 & 0.016 \\
Awe & 2.75 & $\mathbf{0 . 0 0 5}$ & 0.028 & 0.69 & 0.41 & 0.002 & 4.11 & $<\mathbf{0 . 0 0 1}$ & 0.041 \\
Compassion & 3.41 & $<\mathbf{0 . 0 0 1}$ & 0.036 & 14.27 & $<\mathbf{0 . 0 0 1}$ & 0.027 & 4.60 & $<\mathbf{0 . 0 0 1}$ & 0.048 \\
Desire & 2.73 & 0.006 & 0.029 & 2.27 & 0.14 & 0.005 & 3.86 & $<\mathbf{0 . 0 0 1}$ & 0.041 \\
Gratitude & 2.55 & 0.010 & 0.026 & 0.15 & 0.70 & 0.0004 & 2.84 & $\mathbf{0 . 0 0 4}$ & 0.028 \\
Interest & 3.07 & $\mathbf{0 . 0 0 3}$ & 0.031 & 1.93 & 0.17 & 0.005 & 2.17 & 0.033 & 0.022 \\
Love & 1.76 & 0.076 & 0.019 & 1.16 & 0.28 & 0.002 & 2.64 & 0.006 & 0.029 \\
Pride & 7.82 & $<\mathbf{0 . 0 0 1}$ & 0.079 & 3.62 & 0.06 & 0.007 & 1.87 & 0.071 & 0.020 \\
Relief & 4.47 & $<\mathbf{0 . 0 0 1}$ & 0.047 & 0.03 & 0.87 & 0.0006 & 1.89 & 0.065 & 0.020 \\
\hline
\end{tabular}

Note. Significant results are in bold and values are Bonferroni-corrected to alpha $=0.006$.

\section{Amusement}

Amusement was rated high in pleasantness and low in problem and effort. We also found amusement to be high in certainty, as well as in agency of others and oneself. In the two-way ANOVA for amusement, there was no significant effect of culture nor a significant interaction between appraisal and culture. The appraisal pattern of amusement is visualized in Figure 2.

\section{Figure 2}

Appraisal Pattern of Amusement. 


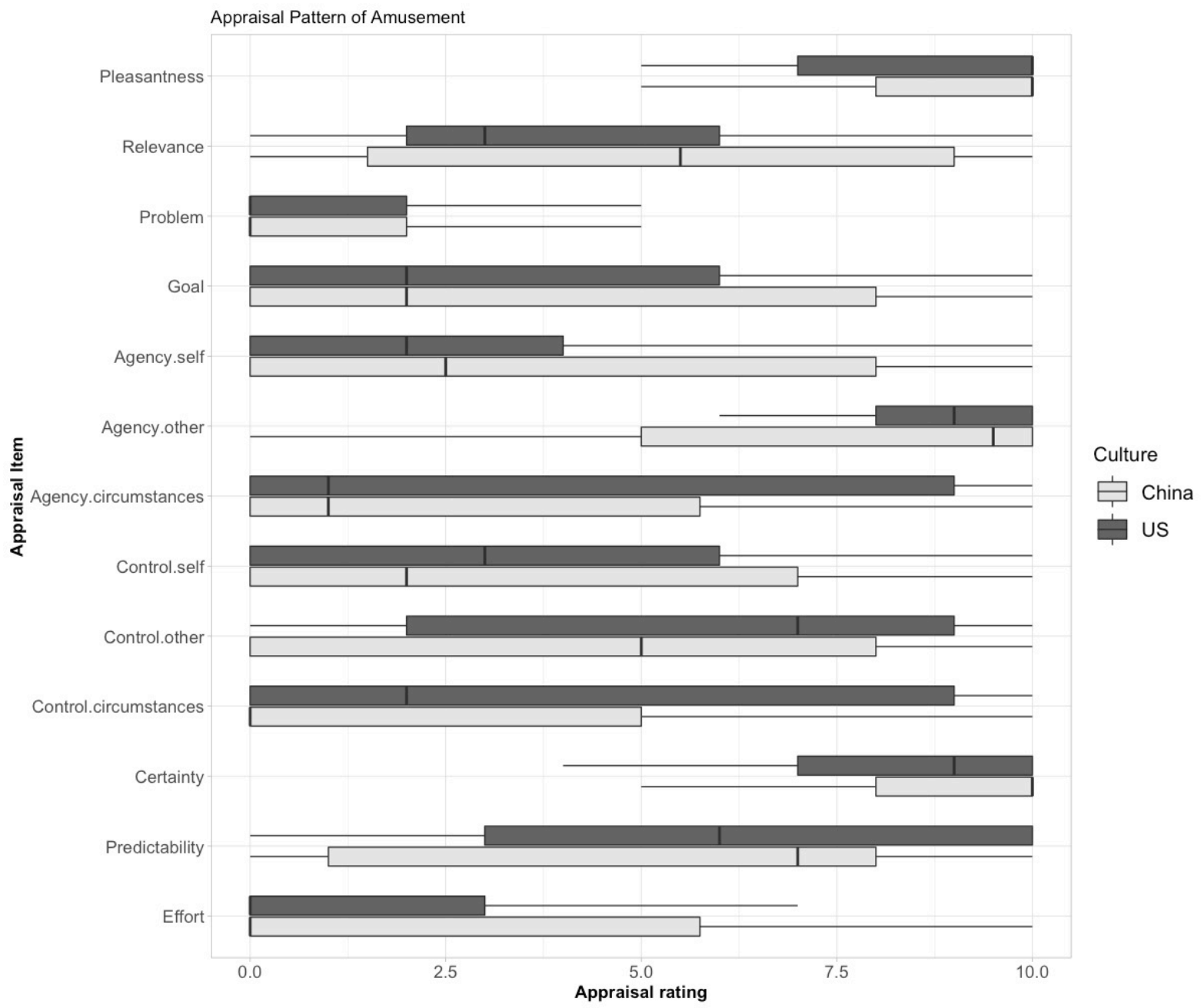

Note. The boxplot indicates the minimum, first quartile, median, third quartile, and maximum of each appraisal item per culture.

Awe

Consistent with previous theorizing and empirical work, we observed high ratings of agency of circumstances and control of circumstances, and low ratings of control by oneself. Additionally, we found that experiences of awe were rated high on certainty and not perceived as involving a problem. The appraisal patterns of awe are illustrated in Figure 3.

The two-way ANOVA revealed a significant interaction effect between culture and appraisal, $F(8.13,626.25)=4.11, p<0.001, \eta^{2}=0.041$. We therefore performed post hoc $\mathrm{t}$ tests comparing each of the appraisal items between the two cultures. The results showed that participants from China and the US differed significantly in their evaluation of pleasantness, 
$t(62.96)=-6.72, \mathrm{p}<0.001, d=-1.38,95 \%$ CI $[-4.64,-2.51$ and effort, $t(77.73)=3.64, \mathrm{p}<$ $0.001, d=0.79,95 \%$ CI $[1.14,3.89]$. Specifically, Chinese participants appraised awe to be less pleasant $(M=5.66, S D=3.50)$ than participants from the US $(M=9.23, S D=1.07)$.

\section{Figure 3}

Appraisal Pattern of Awe

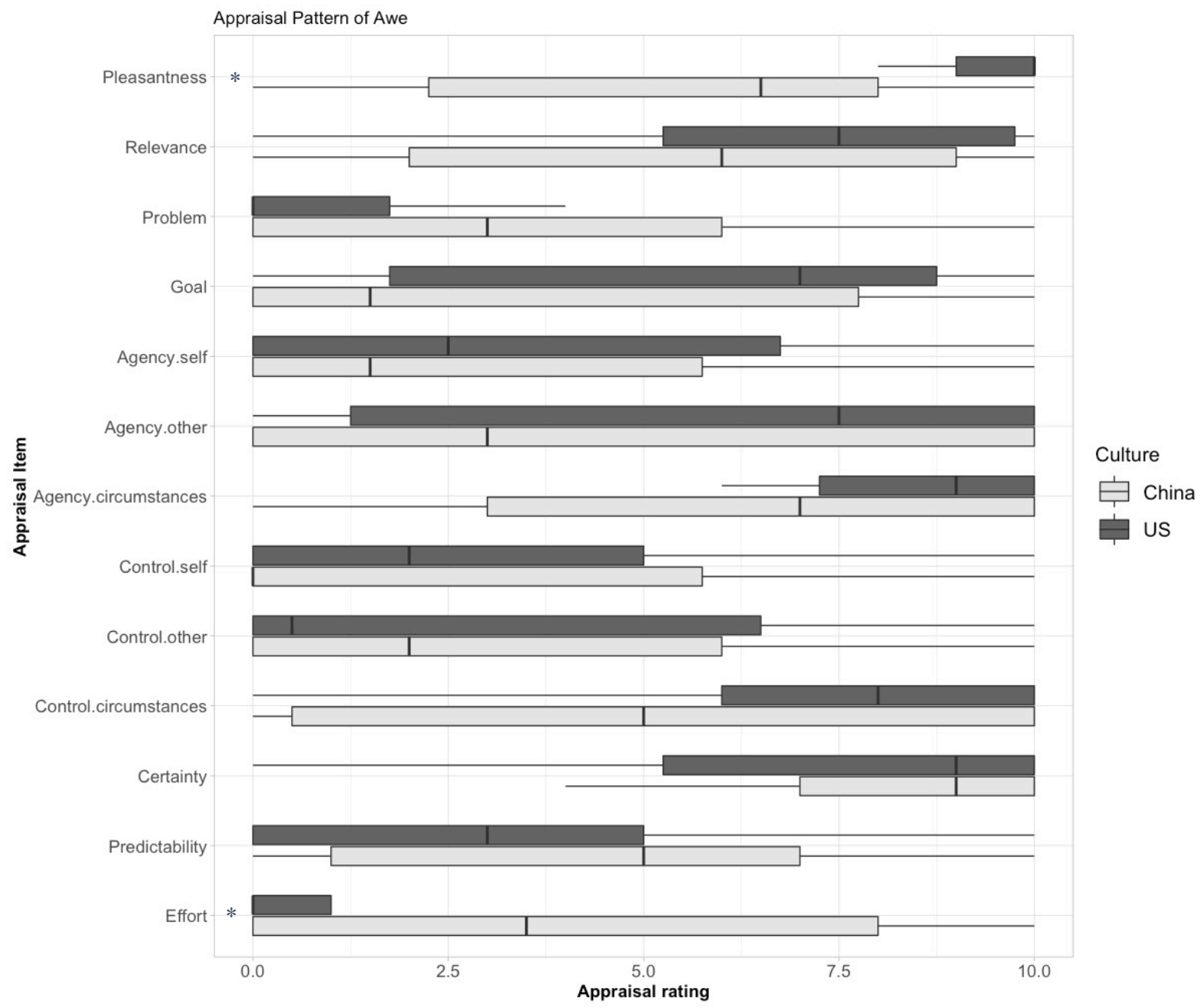

Note. The boxplot indicates the minimum, first quartile, median, third quartile, and maximum of each appraisal item per culture. Asterisks mark the items that differed significantly between the two cultures.

\section{Compassion}

Participants from both cultures judged compassion to be high in agency of others and of the circumstances, while agency and control by the self was rated low. This suggests that 
the experience of compassion is perceived as being caused by others or external forces rather than oneself. The experience of compassion was also rated low on pleasantness.

The two-way ANOVA showed a significant main effect of culture, $F(1,77)=14.27$, $p<0.001, \eta^{2}=0.027$, and a significant interaction effect between culture and appraisals, $F(7.77,597.96)=4.60, p<0.001, \eta^{2}=0.048$. The interaction effect suggests that the appraisal patterns differ between the two cultures. Post hoc t-tests revealed that participants from China and the US differed in their evaluations of pleasantness, $t(50.47)=-3.60, \mathrm{p}<$ $0.001, d=-0.86,95 \%$ CI $[-3.54,-1.01]$, problem, $t(70.24)=-7.53, \mathrm{p}<0.001, d=-1.70,95 \%$ CI $[-6.29,-3.66]$ and goal congruence $t(52.70)=-3.40, \mathrm{p}=0.001, d=-0.80,95 \%$ CI [-4.28, 1.10]. Chinese participants $(M=1.06, S D=2.32)$ perceived compassion to be less pleasant than American participants $(M=3.33, S D=2.95)$. Chinese participants also judged the situation to be less congruent with their goals $\left(M_{C N}=2.24, S D_{C N}=3.03 ; M_{U S}=4.93, S D_{U S}=3.65\right)$ and felt less like there were problems that needed to be solved in the situation $\left(M_{C N}=2.86\right.$, $\left.S D_{C N}=3.19 ; M_{U S}=7.83, S D_{U S}=2.64\right)$.

\section{Figure 4}

Appraisal Pattern of Compassion 




Note. The boxplot indicates the minimum, first quartile, median, third quartile, and maximum of each appraisal item per culture. Asterisks mark the items that differed significantly between the two cultures.

\section{Desire}

The experience of desire was perceived to be high in relevance, effort, and certainty. There was a significant interaction effect between culture and appraisal in the two-way ANOVA, $F(7.74,580.41)=3.86, p<0.001, \eta^{2}=0.041$. Post hoc t-tests revealed that participants from the two cultures differed significantly on their ratings of agency of the circumstances $t(52.84)=-3.52, \mathrm{p}<0.001, d=-0.84,95 \% \mathrm{CI}[-4.71,-1.29]$ and control of the circumstances, $t(47.32)=-4.46, \mathrm{p}<0.001, d=-1.08,95 \%$ CI $[-4.93,-1.87]$. This difference reflected Chinese participants perceiving the desire-evoking event to be less caused $\left(M_{C N}=3.24, S D_{C N}\right.$ 
$\left.=3.33 ; M_{U S}=6.24, S D_{U S}=3.80\right)$ and less controlled $\left(M_{C N}=2.33, S D_{C N}=2.70 ; M_{U S}=5.72\right.$, $\left.S D_{U S}=3.53\right)$ by the circumstances than did participants from the US.

Figure 5

Appraisal Pattern of Desire

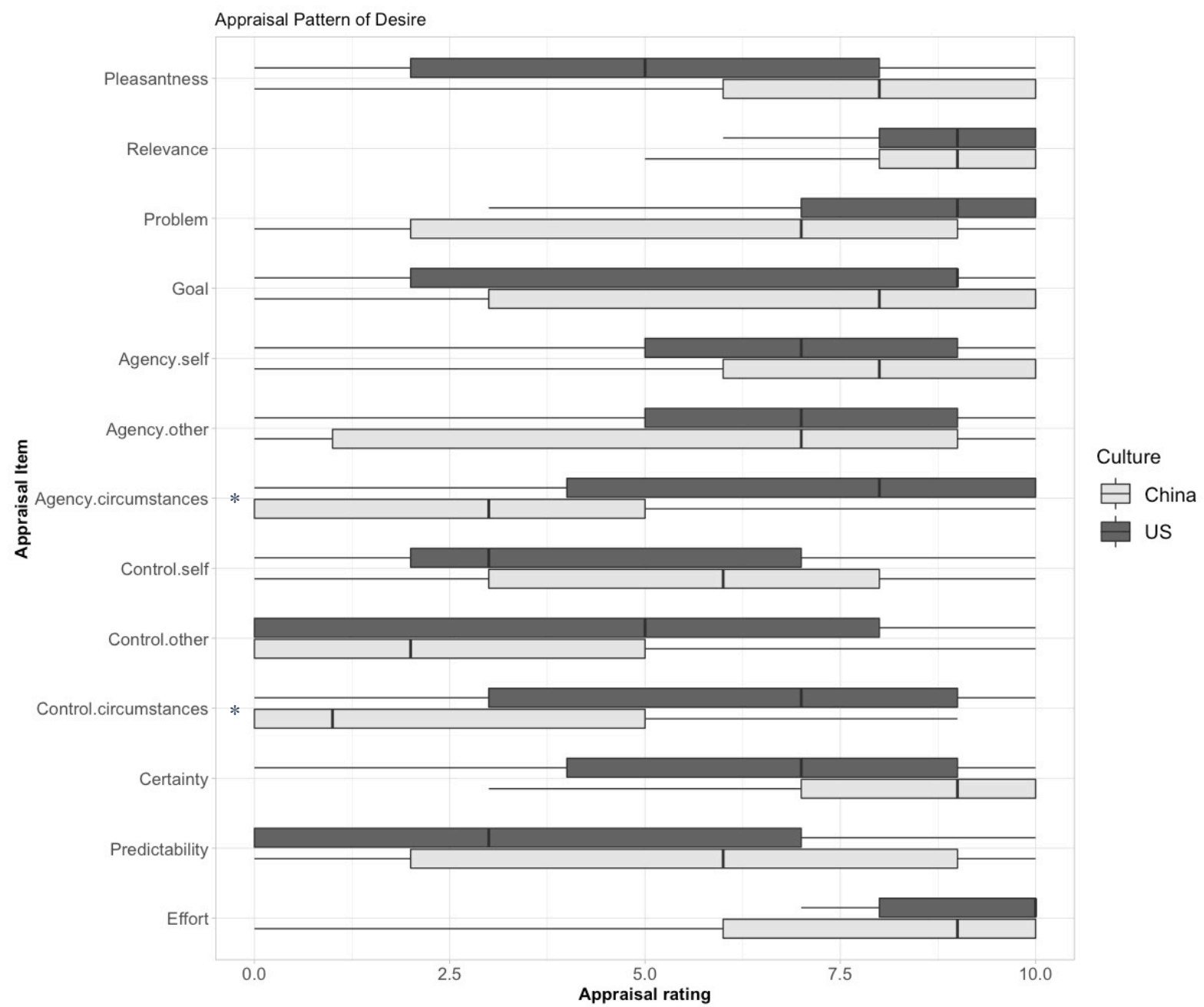

Note. The boxplot indicates the minimum, first quartile, median, third quartile, and maximum of each appraisal item per culture. Asterisks mark the items that differed significantly between the two cultures.

\section{Gratitude}

Gratitude was found to be associated with high levels of pleasantness, relevance, certainty and goal-attainment. We also found gratitude to be rated low in agency and control by circumstances. In the two-way ANOVA, there was a significant interaction effect between culture and appraisal $F(7.91,608.83)=2.84, \mathrm{p}=0.004, \eta^{2}=0.028$. We performed post hoc $\mathrm{t}-$ tests to further investigate the interaction effects. However, differences between the two 
cultures were not statistically significant for any of the appraisal item based on our Bonferroni-adjusted significance level.

\section{Figure 6}

Appraisal Pattern of Gratitude

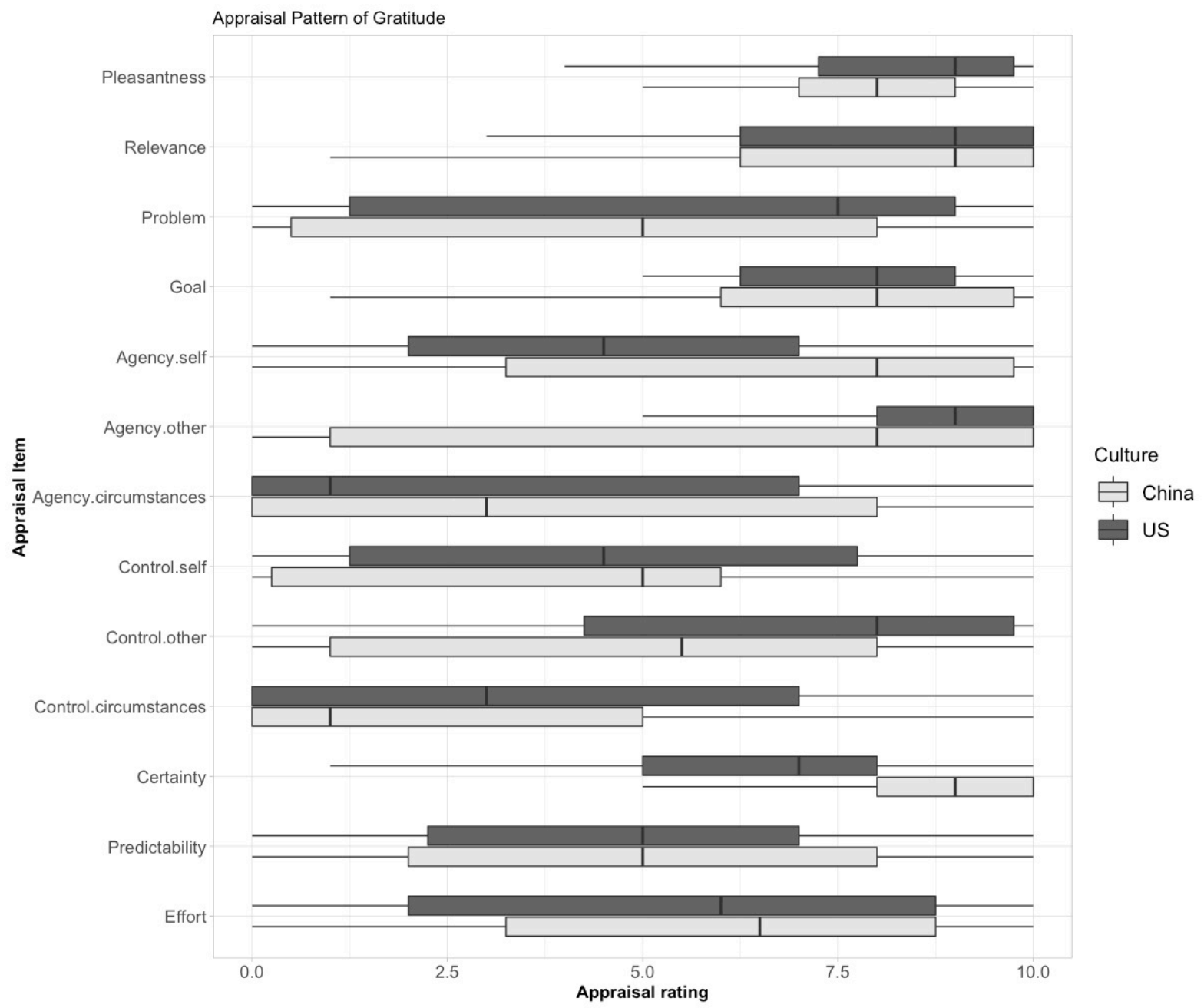

Note. The boxplot indicates the minimum, first quartile, median, third quartile, and maximum of each appraisal item per culture.

\section{Interest}

Interest was rated as being very pleasant, confirming the idea that interest is inherently enjoyable to experience (Smith \& Ellsworth, 1985; Tong, 2015). We also observed high ratings of certainty and relevance. This is consistent with previous theorizing that we are more likely to be interested in things that concern us, and to the extent that we feel able to understand the object (Connelly, 2011; Silvia, 2005, 2008). In the two-way ANOVA, there was 
no significant effect of culture or significant interaction effect between appraisal and culture for any of the appraisal items.

\section{Figure 7}

Appraisal Pattern of Interest

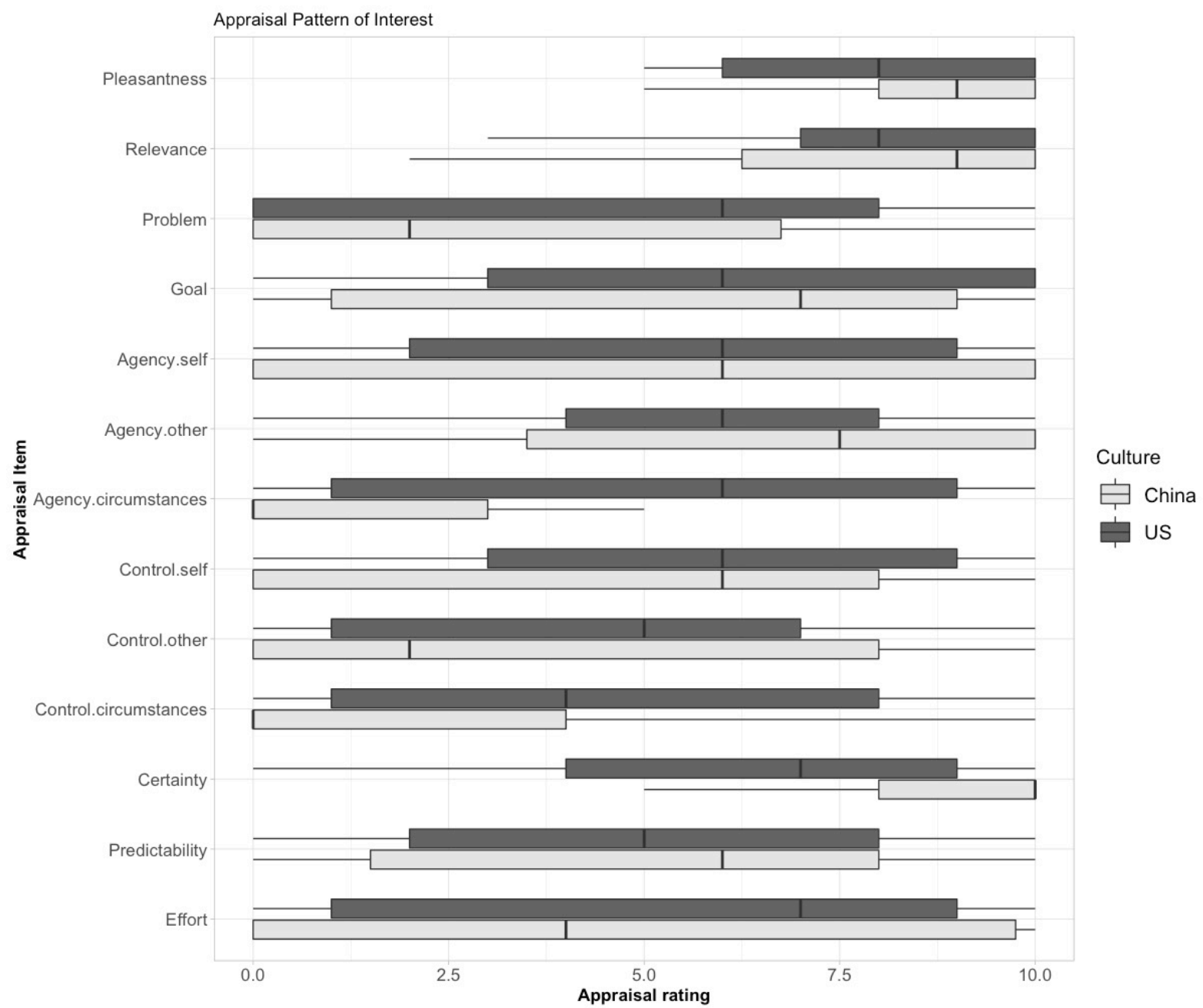

Note. The boxplot indicates the minimum, first quartile, median, third quartile, and maximum of each appraisal item per culture.

\section{Love}

Love was perceived as high in certainty and relevance, meaning that participants considered the event triggering their experience of love to be very relevant and that they were certain of what was going on. Love was also associated with high levels of pleasantness and agency of others. This is consistent with findings from previous research showing that love is very pleasant to experience, and it is often judged to be caused by others (Ellsworth \& Smith, 
1988; Tong, 2015). In the two-way ANOVA test, there was no significant effect of culture or significant interaction effect between appraisal and culture.

\section{Figure 8}

Appraisal Pattern of Love

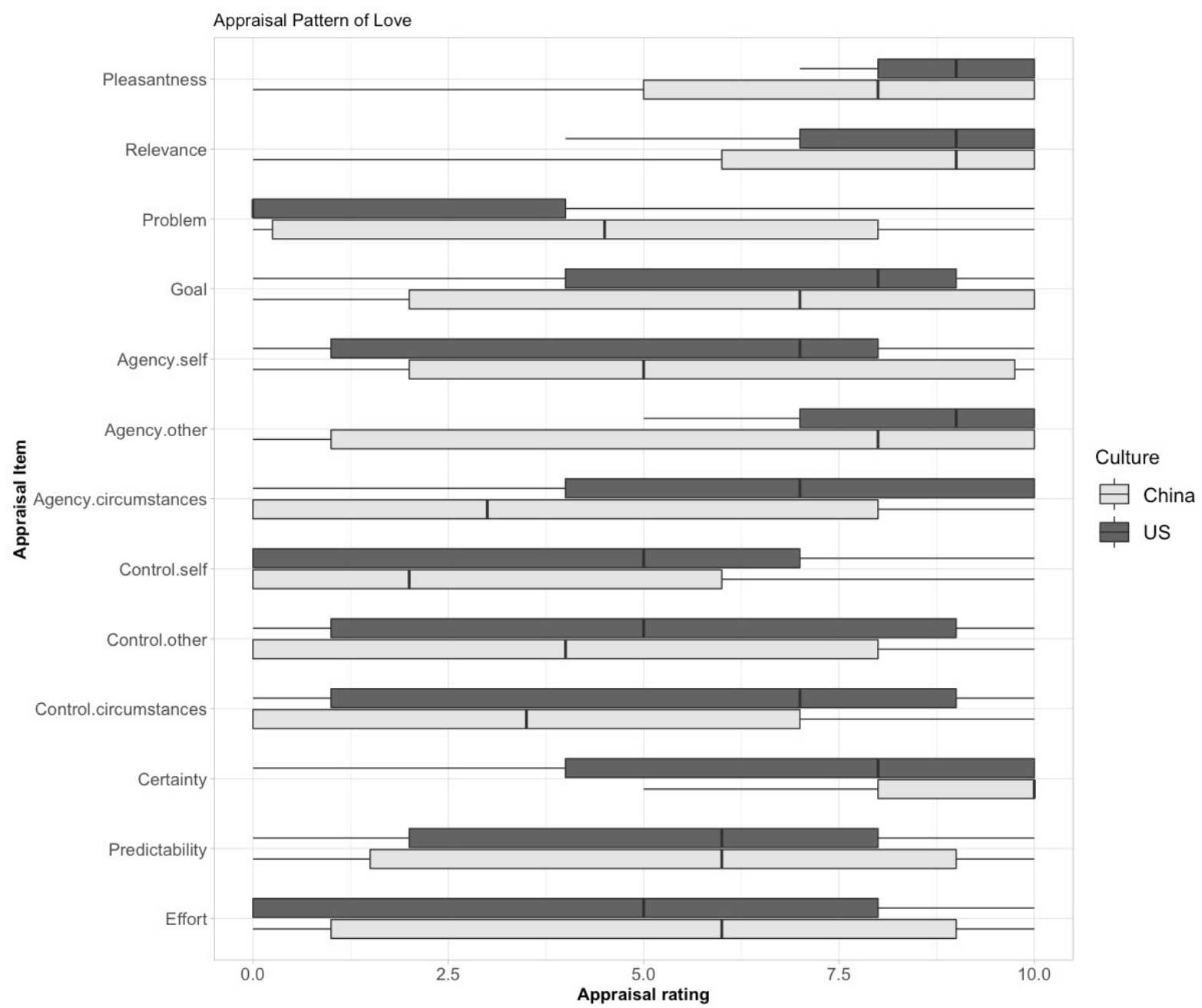

Note. The boxplot indicates the minimum, first quartile, median, third quartile, and maximum of each appraisal item per culture.

\section{Pride}

Pride was rated high in pleasantness, relevance, certainty and goal-attainment. This replicates previous findings that pride is experienced as very positive and that it involves appraised congruence, relevance, and goal-attainment (Frijda et al., 1989; Reisenzein \& Spielhofer, 1994; Roseman et al., 1996; Smith \& Ellsworth, 1985; Tong, 2015; Yih et al., 2020). Also consistent with previous work showing that pride-eliciting events are usually 
perceived as caused by the self rather than external factors (Smith \& Ellsworth, 1985; Tracy \& Robins, 2004; Tong, 2015; Weiner, 1985; Yih et al., 2020), pride was evaluated to be high on agency of the self and low on agency of circumstances and control by circumstances.

None of the appraisal items differed significantly between the two cultures.

\section{Figure 9}

Appraisal Pattern of Pride

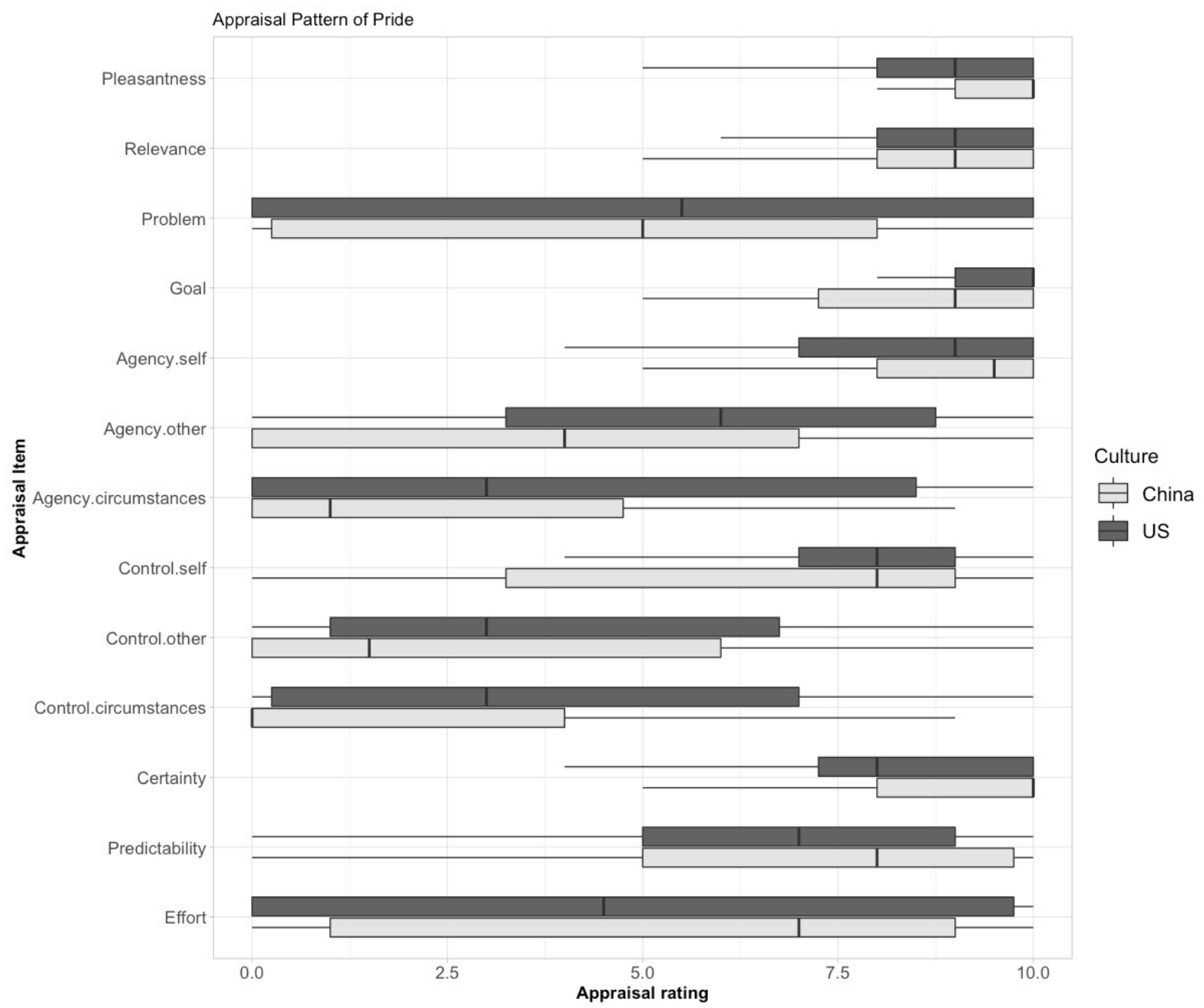

Note. The boxplot indicates the minimum, first quartile, median, third quartile, and maximum of each appraisal item per culture.

\section{Relief}

Participants judged their relief experiences as characterized by problems, goal-attainment, relevance, certainty and pleasantness. This is consistent with previous theorizing that relief is experienced when an important goal almost escaped one's grasp or when an 
undesired outcome of importance is closely avoided (Roseman, 2013; Tong, 2015). Contrary to the previous findings of Tong (2015) and Yih and colleagues (2020), we did not find relief to be associated with accountability of others. The ratings of agency of others, agency of circumstances, control by other and control by circumstances were all rated rather low by participants from both cultures. The two-way ANOVA indicated that none of appraisal items differed significantly between the two cultures.

Figure 10

Appraisal Pattern of Relief

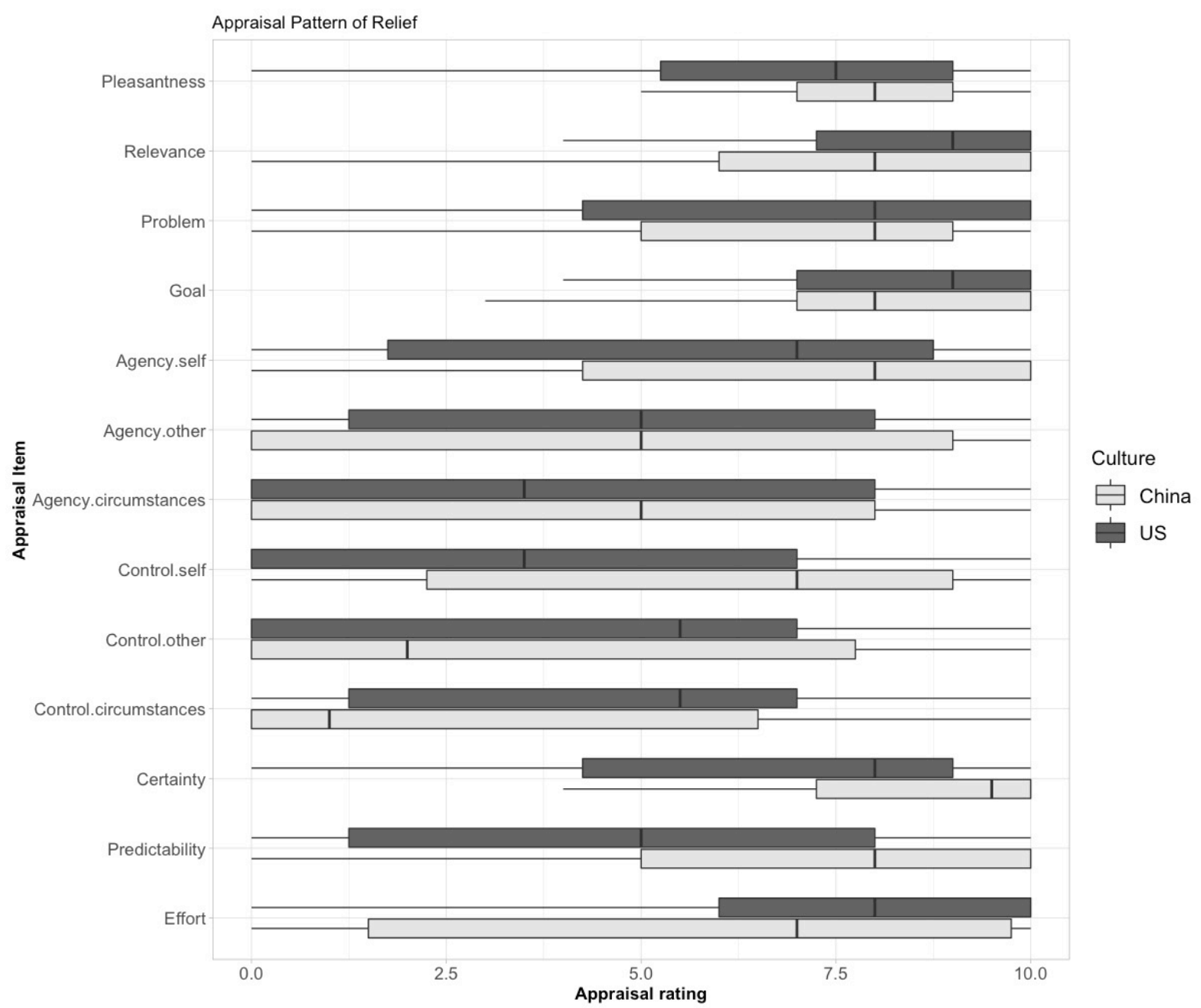

Note. The boxplot indicates the minimum, first quartile, median, third quartile, and maximum of each appraisal item per culture.

\section{Sensitivity Analysis}


Finally, we wanted to examine the statistical power of our analyses. Since we did not conduct a priori power analysis, we now performed a post hoc sensitivity analysis for the critical tests - the simple effect analyses on the cultural variability of specific appraisal dimensions. Using the pwr package in $\mathrm{R}$, we conducted a sensitivity analysis based on the adjusted alpha level of 0.001 . To achieve statistical power of 0.8 , our current sample size is able to detect effects sizes of $d=0.99$ or higher. We discuss the implications of these findings in the discussion.

\section{Discussion}

The current study examined appraisal patterns of nine positive emotions in participants from China and the US. Our results are consistent with findings from previous studies showing that positive emotions can be differentiated based on their appraisal patterns (Tong, 2015; Yih et al., 2020). Additionally, we provide novel evidence for cultural variation in the appraisal patterns of positive emotions. Specifically, we observed cultural variation in appraisals of four of the nine emotions examined: awe, compassion, desire, and gratitude.

We identified distinct appraisal patterns for all nine positive emotions. The overall ANOVA models demonstrated that participants' evaluations differed across the nine positive emotions based on their appraisal ratings. These findings were further supported by discriminant analyses, which showed that all nine positive emotions could be correctly classified at rates much higher than chance based on their appraisal patterns. We now discuss the findings per emotion in turn.

\section{Appraisal Profiles of Positive Emotions}

Participants' experiences of amusement were found to be very enjoyable, characterized by high pleasantness and involving minimal problems or effort. Consistent with previous research arguing that amusement is associated with other-accountability (Scherer \& Ceshi, 1997; Tong, 2015), we also found amusement to be rated high on agency of others and 
oneself. Our findings are thus consistent with previous research on the appraisal profile of amusement (Tong, 2015; Yih et al., 2020). We did not find any significant cultural differences in the appraisals of amusement.

Awe was associated with certainty and other-accountability, reflected in high ratings of control by circumstances and agency of circumstances. This is consistent with previous research suggesting that awe is caused by external stimuli and not by oneself (Keltner \& Haidt, 2003; Shiota et al., 2007). Previous research with North American samples has mostly found awe to be appraised positively (Shiota et al., 2007; Yih et al., 2020), but recent evidence suggests that the valence of awe-evoking experiences can be influenced by culture (Nakayama et al., 2020). Specifically, North Americans tend to feel more positive when they experience awe than do Japanese people. Consistent with this pattern, we found that participants from the US experienced awe to be much more pleasant than participants from China did while Chinese participants perceived awe to be more effortful. These findings provide support for the suggestion by Nakayama and colleagues that North American individuals are more predisposed to feel positive aspects of awe.

Participants from both cultures experienced compassion as externally caused, as reflected in high ratings of agency of other and agency of circumstances, and low ratings of agency of the self. These findings fit well with the assumption that compassion is elicited by the misfortune of someone else, who is often subjected to uncontrollable forces (Goetz et al., 2010). The experience of compassion was also evaluated as being low in pleasantness which is consistent with previous findings demonstrating that exposure to others' suffering leads to increased levels of negative affect (Condon \& Barrett, 2013; Smith et al., 2014; Tong, 2015). Participants from the two cultures differed in their evaluations of how pleasant their experiences of compassion were, and how much of a problem they found there to be in the situation. Specifically, Chinese participants judged compassion eliciting events to be less pleasant, 
but also less problematic. This suggests that despite the unpleasant situation, Chinese individuals did not perceive the situations to involve problems that needed to be solved. This makes sense considering that Chinese participants also considered the situation eliciting compassion to be less in accordance with their goals and wishes. We discuss this effect further in the next section.

Situations eliciting desire were associated with high relevance, effort, and certainty. Desire was not judged as being as pleasant as some of the other emotions, which suggests that anticipation of a reward that still requires effort to achieve may not be as enjoyable as the reward itself. Desire eliciting events were also rated low on control of others, control of circumstances, and agency of circumstances. This suggests that desire was experienced as being driven primarily by oneself. However, participants from the two cultures differed in their evaluations of the extent to which the situation was caused and controlled by the circumstances. Since we did not control the type of desire in our study, the variation in the desireeliciting events participants recalled might have contributed to the cross-cultural variation. Some participants in our study recalled events in which they desired a person, while others recalled events in which they desired an object, and yet others recalled events in which they desired an abstract goal. These variations may have contributed to the cultural variation in what participants considered to be causing and controlling the situation.

Participants in both cultures appraised situations eliciting gratitude to be high in relevance, pleasantness, and goal-attainment, and low in agency and control by circumstances. These findings are in line with previous research on the appraisal patterns of gratitude (Reisenzein \& Spielhofer, 1994; Tong, 2015) and fit well with the notion that gratitude is elicited when a desired outcome is achieved with the help of someone else (McCullough et al., 2001). None of the appraisals differed between the two cultural groups. 
Participants from both cultures evaluated events eliciting interest to be very pleasant, relevant and related to attaining goals. This is in line with previous research on interest showing that we are interested in things that matter to us and that the experience of interest is inherently enjoyable (Connelly, 2011; Silvia, 2005, 2008; Smith \& Ellsworth, 1985; Tong, 2015; Yih et al., 2020). We did not find any significant cultural differences in the appraisals of interest.

We found that love was evaluated as pleasant and relevant. Participants were also very certain of what was going on in the love-eliciting situations. This is consistent with previous research on the appraisal patterns of love (Ellsworth \& Smith, 1988; Tong, 2015). We observed high levels of agency of others, as also reported by Tong (2015). It has been previously suggested that the appraisal profile of love is similar to that of compassion (Yih et al., 2020), perhaps because they serve overlapping functions (Shiota et al., 2004). However, our findings do not provide support for this proposal. Compassion was associated with other accountability, reflected in high ratings of agency of others and circumstances, and low agency and control of the self. Compassion was also evaluated as effortful and unpleasant. Although love was also associated with high agency of others and low control of the self, love was, unlike compassion, evaluated as very pleasant and low in effort and problem. We did not find any significant cultural differences in the appraisals of love. It is noteworthy that in the discriminant analysis, love was not as accurately classified as the other emotions, especially in the Chinese data. This suggests that appraisal patterns of love may not be as distinct as the other positive emotions examined in the current study.

We identified a similar appraisal pattern for pride as what has been established in previous research. Participants from both cultures evaluated the experience of pride to be pleasant, relevant, certain, and related to goal-attainment and self-accountability (Frijda et al., 1989; Reisenzein \& Spielhofer, 1994; Roseman et al., 1996; Smith \& Ellsworth, 1985; Tracy 
\& Robins, 2004; Tong, 2015; Weiner, 1985; Yih et al., 2020). We did not find any significant cultural differences in the appraisals of pride. This lack of cultural differences is in line with the proposal that pride is a basic emotion associated with universally recognized expressions (Tracy \& Robins, 2008).

Relief has been theorized to be elicited by events of uncertainty, often related to uncontrollable external circumstances that later turn into positive certainty, resulting in relief when the desired outcome is achieved (Roseman, 2013; Tong, 2015; Yih et al., 2020). Consistent with these theoretical proposals, we found the experience of relief to be associated with goal-attainment, relevance, certainty, problem and pleasantness. We did not find any significant cultural differences in the appraisals of relief.

\section{Cultural Variations in Appraisal Patterns}

The current study provides a novel demonstration of cultural variation in the appraisals of positive emotions. Our findings add to existing theories on the appraisals of positive emotions, which are primarily based on data from the US. Four of the nine emotions we investigated revealed cultural variations: awe, compassion, desire, and gratitude.

We found, for example, that the experience of awe was considered very effortful and not very pleasant by Chinese individuals. This may relate to the different meanings of the English word “awe” compared to the Chinese equivalent term (敬畏, jìng wèi), which carries more fearsome connotations. Our findings provide empirical support for early theorizing by Lazarus (1991) that awe can be experienced as subjectively positive or negative.

Another example is compassion, which has previously been shown to be associated with high levels of perceived problems to be solved (e.g., Tong, 2015). In our study, this was only the case for American participants, but not for Chinese participants. This may relate to differences in the willingness to engage in actions as a result of feeling compassion. A recent study found that, compared to Australians, participants in Singapore were less likely to 
engage in actions when they felt compassion. (Steindl et al., 2020). The authors related this difference to the tightness versus looseness of cultures (Gelfand et al., 2011), arguing that in tight cultures where norms are strong and permissible behaviors of personal discretion are narrow, compassion is associated with different motivations (see Catarino et. al, 2014). This is in line with research pointing to cross-cultural variation in motivations for being compassionate (Cheon et al., 2013; Mrazek et al., 2013). Since China is also high in tightness (Gelfand et al., 2011; Uz, 2015), participants might be reluctant to engage with their compassion for the same reasons. Future studies on compassion could measure tightness and looseness, as this varies not only across cultures, but also across individuals within a culture. Future research could also directly examine the relationship between appraisals of compassion and individuals' motivation to engage with their compassion by measuring, for example, action tendencies.

Though we identified a few appraisal dimensions that differed between the two cultures on some emotions, the overall appraisal patterns of the positive emotions we examined were quite culturally consistent. Our findings are consistent with the notion that evolved psychological mechanisms result in cultural differences instantiated as variations on common themes, thus emphasizing both preparedness and learning in emotion processes (Kamiloglu et al., 2021).

\section{Appraisal patterns across emotions}

Several appraisal dimensions emerged as key themes across multiple emotions. To start with, there were only a few exceptions to emotions being evaluated as positive. Most emotions were judged as pleasant to experience, with the exception of compassion, and to a lesser extent desire. This fits with the approach of categorizing positive emotions based on the positive valance of the subjective experience (Shiota et al., 2021). Meanwhile, it also shows that different positively valanced affective states can differ on quite a few other 
dimensions, in line with theories of discrete categories of positive emotions (Campos et al., 2013; Hu \& Kaplan, 2015; Sauter, 2010; Shiota et al., 2017).

Another item that was among the most highly rated appraisal dimensions for the majority of the emotions was relevance. This indicates that the events eliciting positive emotions are generally evaluated as relevant. According to functional accounts, emotions help individuals respond to environmental input in a way that furthers one's physical or social survival (Keltner \& Gross, 1999; Revord et al., 2021). Our findings provide support for the argument that positive emotions serve adaptive evolutionary functions (Armenta et al., 2017; Fredrickson, 2001; Revord et al., 2021; Sels et al., 2021).

Another appraisal dimension that was frequently associated with the positive emotions in our study was certainty. Participants were almost always certain of what was happening in the situations that elicited positive emotions. In fact, certainty was among the top three highest rated appraisals for every single one of the nine emotions we examined, suggesting that positive emotions are generally associated with certainty. There is evidence showing that uncertainty is aversive and triggers negative affective reactions (FeldmanHall, 2019; Grupe, 2013; Hirsh et al., 2012). It is therefore likely that certainty relates to positive affective reactions. Future research could investigate whether these effects generalize to other positive emotions.

On the other hand, not all appraisal dimensions were relevant to the emotions we examined. For example, predictability was never among the highest or lowest rated items for any of the nine emotions. This suggests that predictability may not be a particularly important feature of positive emotion experiences. This might reflect that the appraisal dimensions used in this study were developed mainly for research into negative emotions.

\section{Limitations and Implications}


There are several issues that limit the generalizability of the current study. First, all appraisal dimensions were measured with a single item. Though this is common practice in appraisal research, it limits the reliability of the measurements. Future research might try to establish standard appraisal questionnaires with validated psychometric reliability. Future research could also benefit from developing appraisal items that are particularly relevant for positive emotions, since appraisals that characterize positive emotions might differ from those for negative emotions.

Secondly, the choice of the emotions examined in the current study, though based on previous research, was somewhat arbitrary. Some of the emotions we examined were not particularly subjectively pleasant, and would therefore according to some criteria not be counted as positive (Shiota et al., 2021). Recent efforts have been made to systematically classify positive emotions based on their functions (Revord et al., 2021), subjective experience (Weidman \& Tracy, 2020), or physiological responses and expressive behaviors (Keltner \& Cowan, 2021). Future research could adopt a more systematic approach in selecting emotions to study, drawing insights from these theoretical developments.

Thirdly, participants in our study were free to recall any eliciting event, as long as it was associated with the particular emotion they were instructed to recall. Though we made efforts to ensure participants were all recalling events for the target emotion, there was still considerable variability in the kinds of events recalled. For example, we did not impose any limitations on whether the situation was social or not, or how long ago it occurred. This freedom might have influenced some emotions more than others. For example, love can be experienced quite differently when it is love for a child compared to when it is love for a romantic partner (Hendrick \& Hendrick, 1986). Future research could either control or measure these factors in order to explain more variance in the appraisal patterns. 
Fourthly, we did not analyze the content of participants' emotional stories beyond the appraisal questions. Examining the details of these stories could give further insights into participants' emotional experiences and appraisals. For example, qualitative analyses of these data might yield insights about why participants evaluated certain situations in certain ways. To investigate what drives these appraisal patterns and cultural differences, future research may consider qualitative or mixed methods studies.

Lastly, our sample size of 80 participants is fairly small, especially for a cross-cultural study. Though both emotion condition and appraisal items were within-subject factors, thus maximizing statistical power, the between-culture effects may still have limited power. In the sensitivity analyses we found that to achieve the ideal power of at least .80 recommended for psychological studies (Anderson et al., 2017), our sample was only able to detect effect sizes larger than $d=0.99$. The significant effects observed in our study range between 0.8 and 1.7 , meaning that some of the effects are underpowered. Moreover, we used a convenience sample from the community and did not measure demographic information such as social economic status. These findings may thus not be representative of the broader populations. Future studies should aim for larger and more representative samples and consider measuring a wider range of demographic features.

\section{Conclusion}

The current study investigated the appraisal patterns of nine positive emotions in two cultures. We profiled the appraisal patterns of amusement, awe, compassion, desire, gratitude, interest, pride, and relief. In addition to identifying emotion-specific appraisal patterns, we also, for the first time, demonstrated cultural variations in the appraisals of positive emotions. We showed that individuals' evaluations of emotion-eliciting events differed across cultures on appraisal dimensions, including pleasantness and the extent to which they 
involved a problem. Our results highlight the importance of cross-cultural work on the appraisals of positive emotions. 


\section{Declarations}

\section{Funding}

The preparation of this manuscript was supported by grant 714977 from the European Research Council (ERC) to D.A.S. and grant 2523.0251.01 from the Dutch Research Council (Nederlandse Organisatie voor Wetenschappelijk Onderzoek) to D.A.S and Y.C.

\section{Conflict of interest}

On behalf of all authors, the corresponding author states that there is no conflict of interest.

\section{Availability of data and materials}

All associated data and analysis files for this manuscript can be found in our project on OSF:

https://osf.io/jc4br/?view_only=9f41bdea3c1042679a43bdda512e5b6b 


\section{References}

Algoe, S. B., Haidt, J., \& Gable, S. L. (2008). Beyond reciprocity: Gratitude and relationships in everyday life. Emotion, 8, 425-429. https://doi.org/10.1037/1528-3542.8.3.425

Anderson, S. F., Kelley, K., \& Maxwell, S. E. (2017). Sample-size planning for more accurate statistical power: A method adjusting sample effect sizes for publication bias and uncertainty. Psychological science, 28(11), 1547-1562.

https://doi.org/10.1177\%2F0956797617723724

Armenta, C. N., Fritz, M. M., \& Lyubomirsky, S. (2017). Functions of positive emotions: Gratitude as a motivator of self-improvement and positive change. Emotion Review, 9(3), 183-190. https://doi.org/10.1177\%2F1754073916669596

Bai, Y., Maruskin, L. A., Chen, S., Gordon, A. M., Stellar, J. E., McNeil, G. D., ... \& Keltner, D. (2017). Awe, the diminished self, and collective engagement: Universals and cultural variations in the small self. Journal of personality and social psychology, 113(2), 185209. https://doi.org/10.1037/pspa0000087

Bartlett, M. Y., \& DeSteno, D. (2006). Gratitude and prosocial behavior: Helping when it costs you. Psychological Science, 17, 319-325. https://doi.org/10.1111/j.14679280.2006.01705.x

Berridge, K. C. (2009). Wanting and liking: Observations from the neuroscience and psychology laboratory. Inquiry, 52(4), 378-398.

https://doi.org/10.1080/00201740903087359

Boiger, M., Güngör, D., Karasawa, M., \& Mesquita, B. (2014). Defending honour, keeping face: Interpersonal affordances of anger and shame in Turkey and Japan. Cognition and Emotion, 28, 1255-1269. https://doi.org/10.1080/02699931.2014.881324

Bowlby, J. (1979). The bowlby-ainsworth attachment theory. Behavioral and Brain Sciences, 2(4), 637-638. https://doi.org/10.1017/S0140525X00064955

Borke, H., \& Su, S. (1972). Perception of emotional responses to social interactions by Chinese and American children. Journal of Cross-Cultural Psychology, 3(3), 309-314. https://doi.org/10.1177/002202217200300309

Campos, B., Shiota, M. N., Keltner, D., Gonzaga, G. C., \& Goetz, J. L. (2013). What is shared, what is different? Core relational themes and expressive displays of eight positive emotions. Cognition \& Emotion, 27(1), 37-52.

https://doi.org/10.1080/02699931.2012.683852

CatariNo, F., Gilbert, P., MCewaN, K., \& Baião, R. (2014). Compassion motivations: Distinguishing submissive compassion from genuine compassion and its association with shame, submissive behavior, depression, anxiety and stress. Journal of Social and Clinical Psychology, 33(5), 399-412. 
Cheon, B. K., Mrazek, A. J., Pornpattananangkul, N., Blizinsky, K. D., \& Chiao, J. Y. (2013). Constraints, catalysts and coevolution in cultural neuroscience: Reply to commentaries. Psychological inquiry, 24(1), 71-79. https://doi.org/10.1080/1047840X.2013.773599

Chirico, A., \& Yaden, D. B. (2018). Awe: a self-transcendent and sometimes transformative emotion. In The function of emotions (pp. 221-233). Springer, Cham. https://doi.org/10.1007/978-3-319-77619-4_11

Condon, P., \& Feldman Barrett, L. (2013). Conceptualizing and experiencing compassion. Emotion, 13(5), 817.

Connelly, D. A. (2011). Applying Silvia's model of interest to academic text: Is there a third appraisal?. Learning and Individual Differences, 21(5), 624-628. https://doi.org/10.1016/j.lindif.2011.04.007

Cordaro, D. T., Sun, R., Keltner, D., Kamble, S., Huddar, N., \& McNeil, G. (2018). Universals and Cultural Variations in 22 Emotional Expressions Across Five Cultures. Emotion (Washington, D.C.), 18(1), 75-93. https://doi.org/10.1037/emo0000302

De Rivera, J., Possell, L., Verette, J. A., \& Weiner, B. (1989). Distinguishing elation, gladness, and joy. Journal of Personality and Social Psychology, 57(6), 1015. https://doi.org/10.1037/0022-3514.57.6.1015

Ekman, P. (1992). An argument for basic emotions. Cognition \& Emotion, 6(3), 169-200. https://doi.org/10.1080/02699939208411068

Elfenbein, H. A. (2007). 7 Emotion in organizations: a review and theoretical integration. Academy of management annals, 1(1), 315-386. https://doi.org/10.5465/078559812

Ellsworth, P. C., \& Smith, C. A. (1988). Shades of Joy: Patterns of Appraisal Differentiating Pleasant Emotions. Cognition \& Emotion, 2(4), 301-331. https://doi.org/10.1080/02699938808412702

Fang, X., Sauter, D. A., \& van Kleef, G. A. (2020). Unmasking smiles: The influence of culture and intensity on interpretations of smiling expressions. Journal of Cultural Cognitive Science, 4(3), 293-308. https://doi.org/10.1007/s41809-019-00053-1

Fischer, K.W., \& Ayoub, C. (2013). Analyzing development of working models of close relationships: Illustration with a case of vulnerability and violence. In G.G. Noam \& K.W. Fischer (Eds.), Development and vulnerability in close relationships. New Jersey: Lawrence Erlbaum Associates.

Fredrickson, B. L. (2001). The role of positive emotions in positive psychology: the broadenand-build theory of positive emotions. American psychologist, 56(3), 218.

Frijda, N. H. , Kuipers, P. , \& ter Schure, E. (1989). Relations among emotion, appraisal, and emotional action readiness. Journal of Personality and Social Psychology , 57, 212-228. https://doi.org/10.1037/0022-3514.57.2.212 
FeldmanHall, O., \& Shenhav, A. (2019). Resolving uncertainty in a social world. Nature human behaviour, 3(5), 426-435. https://doi.org/10.1038/s41562-019-0590-x

Gelfand, M. J., Raver, J. L., Nishii, L., Leslie, L. M., Lun, J., Lim, B. C., ... \& Yamaguchi, S. (2011). Differences between tight and loose cultures: A 33-nation study. Science, 332(6033), 1100-1104. DOI: 10.1126/science.1197754

Gilbert, P., McEwan, K., Matos, M., \& Rivis, A. (2011). Fears of compassion: Development of three self-report measures. Psychology and Psychotherapy: Theory, research and practice, 84(3), 239-255. https://doi.org/10.1348/147608310X526511

Goetz, J. L., Keltner, D., \& Simon-Thomas, E. (2010). Compassion: an evolutionary analysis and empirical review. Psychological bulletin, 136(3), 351-374. https://doi.org/10.1037/a0018807

Graham, L. E., Thomson, A. L., Nakamura, J., Brandt, I. A., \& Siegel, J. T. (2017). Finding a family: A categorization of enjoyable emotions. The Journal of Positive Psychology, 14(2), 206-229. https://doi.org/10.1080/17439760.2017.1402074

Grupe, D. W., \& Nitschke, J. B. (2013). Uncertainty and anticipation in anxiety: an integrated neurobiological and psychological perspective. Nature Reviews Neuroscience, 14(7), 488501. https://doi.org/10.1038/nrn3524

Hendrick, C., \& Hendrick, S. (1986). A theory and method of love. Journal of personality and social psychology, 50(2), 392.

Henrich, J., \& Gil-White, F. J. (2001). The evolution of prestige: Freely conferred deference as a mechanism for enhancing the benefits of cultural transmission. Evolution and human behavior, 22(3), 165-196. https://doi.org/10.1016/S1090-5138(00)00071-4

Hirsh, J. B., Mar, R. A., \& Peterson, J. B. (2012). Psychological entropy: a framework for understanding uncertainty-related anxiety. Psychological review, 119(2), 30. https://psycnet.apa.org/doi/10.1037/a0026767

Hong, Y. Y., Morris, M. W., Chiu, C. Y., \& Benet-Martinez, V. (2000). Multicultural minds: A dynamic constructivist approach to culture and cognition. American Psychologist, 55(7), 709-720. https://doi.org/10.1037/0003-066X.55.7.709

Hu, X., \& Kaplan, S. (2015). Is "feeling good" good enough? Differentiating discrete positive emotions at work. Journal of Organizational Behavior, 36(1), 39-58. https://doi.org/10.1002/job.1941

Kamiloglu, R., Cong, Y. Q., Sun, R., \& Sauter, D. (2021). Emotions Across Cultures. https://doi.org/10.31219/osf.io/9e3sn

Keltner, D., \& Cowen, A. (2021). A taxonomy of positive emotions. Current Opinion in Behavioral Sciences, 39, 216-221. https://doi.org/10.1016/j.cobeha.2021.04.013 
Keltner, D., \& Gross, J. J. (1999). Functional accounts of emotions. Cognition \& Emotion, 13(5), 467-480. https://doi.org/10.1080/026999399379140

Kitayama, S., Karasawa, M., Curhan, K. B., Ryff, C. D., \& Markus, H. R. (2010). Independence and interdependence predict health and wellbeing: Divergent patterns in the United States and Japan. Frontiers in psychology, 1, 163. https://doi.org/10.3389/fpsyg.2010.00163

Kitayama, S., \& Park, J. (2010). Cultural neuroscience of the self: Understanding the social grounding of the brain. Social cognitive and affective neuroscience, 5(2-3), 111-129. https://doi.org/10.1093/scan/nsq052

Kawahara, M., Sauter, D. A., \& Tanaka, A. (2021). Culture shapes emotion perception from faces and voices: changes over development. Cognition and Emotion, 1-12. https://doi.org/10.1080/02699931.2021.1922361

Keltner, D., \& Haidt, J. (2003). Approaching awe, a moral, spiritual, and aesthetic emotion. Cognition and emotion, 17(2), 297-314. https://doi.org/10.1080/02699930302297

Laukka, P., Elfenbein, H. A., Söder, N., Nordström, H., Althoff, J., Chui, W., Iraki, F. K., Rockstuhl, T., \& Thingujam, N. S. (2013). Cross-cultural decoding of positive and negative non-linguistic emotion vocalizations. Frontiers in Psychology, 4, 353. https://doi.org/10.3389/fpsyg.2013.00353

Laukka, P., Elfenbein, H. A., Thingujam, N. S., Rockstuhl, T., Iraki, F. K., Chui, W., \& Althoff, J. (2016). The expression and recognition of emotions in the voice across five nations: A lens model analysis based on acoustic features. Journal of personality and social psychology, 111(5), 686-705. https://doi.org/10.1037/pspi0000066

Lazarus, R. S. (1991). Emotion and adaptation. Oxford University Press on Demand.

Matsumoto, D., Kudoh, T., Scherer, K., \& Wallbott, H. (1988). Antecedents of and reactions to emotions in the United States and Japan. Journal of Cross-Cultural Psychology, 19(3), 267-286. https://doi.org/10.1177/0022022188193001

Mauro, R., Sato, K., \& Tucker, J. (1992). The Role of Appraisal in Human Emotions: A Cross-Cultural Study. Journal of Personality and Social Psychology, 62(2), 301-317. https://doi.org/10.1037/0022-3514.62.2.301

McCullough, M. E. , Kilpatrick, S. D. , Emmons, R. A. , \& Larson, D. B. (2001). Is gratitude a moral affect. Psychological Bulletin , 127 , 249-266. https://doi.org/10.1037/0033$\underline{2909.127 .2 .249}$

McGraw, A. P., \& Warren, C. (2010). Benign violations: Making immoral behavior funny. Psychological science, 21(8), 1141-1149. https://doi.org/10.1177/0956797610376073 
Mesquita, B., and Ellsworth, P. C. (2001). The role of culture in appraisal. In Scherer, K. R., Schorr, A., and Johnson, T. (eds.), Appraisal Processes in Emotion: Theory, Methods, Research, Oxford University Press, New York, pp. 233-248.

Mesquita, B., \& Frijda, N. H. (1992). Cultural Variations in Emotions: A Review. Psychological Bulletin, 112(2), 179-204. https://doi.org/10.1037/0033$\underline{2909.112 .2 .179}$

Moors, A., Ellsworth, P. C., Scherer, K. R., \& Frijda, N. H. (2013). Appraisal Theories of Emotion: State of the Art and Future Development. Emotion Review, 5(2), 119-124. https://doi.org/10.1177/1754073912468165

Morreall, J. (1989). Enjoying incongruity. Humor - International Journal of Humor Research, 2(1), 1-18. https://doi.org/10.1515/humr.1989.2.1.1

Nakayama, M., Nozaki, Y., Taylor, P. M., Keltner, D., \& Uchida, Y. (2020). Individual and cultural differences in predispositions to feel positive and negative aspects of awe. Journal of Cross-Cultural Psychology, 51(10), 771-793.

Oishi, S. (2002). The experiencing and remembering of well-being: A cross-cultural analysis. Personality and Social Psychology Bulletin, 28(10), 1398-

1406. https://doi.org/10.1177/014616702236871

Piff, P. K., Dietze, P., Feinberg, M., Stancato, D. M., \& Keltner, D. (2015). Awe, the small self, and prosocial behavior. Journal of Personality and Social Psychology, 108(6), 883899. https://doi.org/10.1037/pspi0000018

R Core Team (2020). R: A language and environment for statistical computing. R Foundation for Statistical Computing, Vienna, Austria. https://www.R-project.org/

Revord, J., Sweeny, K., \& Lyubomirsky, S. (2021). Categorizing the function of positive emotions. Current Opinion in Behavioral Sciences, 39, 93-97. https://doi.org/10.1016/j.cobeha.2021.03.001

Reisenzein, R., \& Spielhofer, C. (1994). Subjectively salient dimensions of emotional appraisal. Motivation and emotion, 18(1), 31-77. https://doi.org/10.1007/BF02252474

Robinson, M. J. F., Fischer, A. M., Ahuja, A., Lesser, E. N., \& Maniates, H. (2015). Roles of "wanting" and "liking" in motivating behavior: gambling, food, and drug addictions. Behavioral neuroscience of motivation, 105-136

Roseman, I. J., Dhawan, N., Rettek, S. I., Naidu, R. K., \& Thapa, K. (1995). Cultural differences and cross-cultural similarities in appraisals and emotional responses. Journal of cross-cultural psychology, 26(1), 23-38. https://doi.org/10.1177\%2F002202219502600101

Roseman, I. J., Antoniou, A. A., \& Jose, P. E. (1996). Appraisal Determinants of Emotions: Constructing a More Accurate and Comprehensive Theory. Cognition and Emotion, 10(3), 241-278. https://doi.org/10.1080/026999396380240 
Roseman, I. J. (2013). Appraisal in the emotion system: Coherence in strategies for coping. Emotion Review, 5(2), 141-149. https://doi.org/10.1177/1754073912469591

Roseman, I. J., Spindel, M. S., \& Jose, P. E. (1990). Appraisals of emotion-eliciting events: Testing a theory of discrete emotions. Journal of personality and social psychology, 59(5), 899 -915. https://doi.org/10.1037/0022-3514.59.5.899

Sauter, D. (2010). More than happy: The need for disentangling positive emotions. Current Directions in Psychological Science, 19(1), 36-40. https://doi.org/10.1177\%2F0963721409359290

Sauter, D. A. (2017). The Nonverbal Communication of Positive Emotions: An Emotion Family Approach. Emotion Review, 9(3), 222-234. https://doi.org/10.1177/1754073916667236

Sauter, D. A., Eisner, F., Ekman, P., \& Scott, S. K. (2015). Emotional Vocalizations Are Recognized Across Cultures Regardless of the Valence of Distractors. Psychological Science, 26(3), 354-356. https://doi.org/10.1177/0956797614560771

Scherer, K. R. (1997). The Role of Culture in Emotion-Antecedent Appraisal. Journal of Personality and Social Psychology, 73(5), 902-922. https://doi.org/10.1037/0022$\underline{3514.73 .5 .902}$

Scherer, K. R. (1999). Appraisal theory. In T. Dalgleish \& M. J. Power (Eds.), Handbook of cognition and emotion (pp. 637-663). John Wiley \& Sons

Ltd. https://doi.org/10.1002/0470013494.ch30

Scherer, K. R., \& Ceshi, G. (1997). Lost luggage: A field study of emotion-antecedent appraisal. Motivation \& Emotion, 21, 211-235. https://doi.org/10.1023/ A:1024498629430

Scherer, K. R., \& Wallbott, H. G. (1994). Evidence for universality and cultural variation of differential emotion response patterning. Journal of personality and social psychology, 66(2), 310 -328. https://doi.org/10.1037/0022-3514.66.2.310

Scherer, K. R., Wallbott, H. G., \& Summerfield, A. B. (1986). Experiencing emotion: A cross-cultural study. Cambridge, England: Cambridge University Press.

Schroeder, T. (2006). Desire. Philosophy Compass, 1(6), 631-639. https://doi.org/10.1111/j.1747-9991.2006.00047.x

Sels, L., Tran, A., Greenaway, K. H., Verhofstadt, L., \& Kalokerinos, E. K. (2021). The social functions of positive emotions. Current Opinion in Behavioral Sciences, 39, 41-45. https://doi.org/10.1016/j.cobeha.2020.12.009

Shiota, M. N., Campos, B., \& Keltner, D. (2003). The faces of positive emotion. Annals of the New York Academy of Sciences, 1000(1), 296-299. 
Shiota, M. N., Campos, B., Keltner, D., \& Hertenstein, M. J. (2004). Positive emotion and the regulation of interpersonal relationships. In The Regulation of Emotion (pp. 129-157). https://doi.org/10.4324/9781410610898

Shiota, M. N., Campos, B., Oveis, C., Hertenstein, M. J., Simon-Thomas, E., \& Keltner, D. (2017). Beyond Happiness: Building a Science of Discrete Positive Emotions. American Psychologist, 72(7), 617-643. https://doi.org/10.1037/a0040456

Shiota, M. N., Keltner, D., \& Mossman, A. (2007). The nature of awe: Elicitors, appraisals, and effects on self-concept. Cognition and Emotion, 21(5), 944-963. https://doi.org/10.1080/02699930600923668

Shiota, M. N., Neufeld, S. L., Danvers, A. F., Osborne, E. A., Sng, O., \& Yee, C. I. (2014). Positive Emotion Differentiation: A Functional Approach. Social and Personality Psychology Compass, 8(3), 104-117. https://doi.org/10.1111/spc3.12092

Shiota, M. N., Neufeld, S. L., Yeung, W. H., Moser, S. E., \& Perea, E. F. (2011). Feeling Good: Autonomic Nervous System Responding in Five Positive Emotions. Emotion, 11(6), 1368-1378. https://doi.org/10.1037/a0024278

Shiota, M. N., Sauter, D. A., \& Desmet, P. M. (2021). What are 'positive' affect and emotion?. Current Opinion in Behavioral Sciences, 39, 142-146. https://doi.org/10.1016/j.cobeha.2021.03.007

Silvia, P. J. (2008). Interest-The curious emotion. Current directions in psychological science, 17(1), 57-60. https://doi.org/10.1111/j.1467-8721.2008.00548.x

Silvia, P. J. (2005). What is interesting? Exploring the appraisal structure of interest. Emotion , 5 , 89-102. https://doi.org/10.1037/1528-3542.5.1.89

Sim, S. F. (2001). Asian values, authoritarianism and capitalism in Singapore. Javnost-The Public, 8(2), 45-66.

Sklair, L. (2001). The transnational capitalist class (Vol. 17). Oxford: Blackwell.

Smith, C. A. , \& Ellsworth, P. C. (1985). Patterns of cognitive appraisal in emotion. Journal of Personality and Social Psychology , 48 , 813-838. https://doi.org/10.1037/00223514.48.4.813

Smith, S., Gentleman, M., Loads, D., \& Pullin, S. (2014). An exploration of a restorative space: A creative approach to reflection for nurse lecturer's focused on experiences of compassion in the workplace. Nurse Education Today, 34(9), 1225-1231. https://doi.org/10.1016/j.nedt.2014.03.003

Steindl, S. R., Yiu, R. X. Q., Baumann, T., \& Matos, M. (2020). Comparing compassion across cultures: Similarities and differences among Australians and Singaporeans. Australian Psychologist, 55(3), 208-219. https://doi.org/10.1111/ap.12433

Stellar, J. E., Gordon, A. M., Piff, P. K., Cordaro, D., Anderson, C. L., Bai, Y., ... \& Keltner, D. (2017). Self-transcendent emotions and their social functions: Compassion, gratitude, 
and awe bind us to others through prosociality. Emotion Review, 9(3), 200-207. https://doi.org/10.1177/1754073916684557

Sung, B., \& Yih, J. (2015). Does interest broaden or narrow attentional scope? Cognition and Emotion, 30, 1485-1494. https://doi.org/10.1080/02699931.2015.1071241

Tong, E. M. W. (2015). Differentiation of 13 positive emotions by appraisals. Cognition and Emotion, 29(3), 484-503. https://doi.org/10.1080/02699931.2014.922056

Tong, E. M., \& Jia, L. (2017). Positive emotion, appraisal, and the role of appraisal overlap in positive emotion co-occurrence. Emotion, 17(1), 40-54.

https://doi.org/10.1037/emo0000203

Tracy, J. L., \& Robins, R. W. (2007). Emerging insights into the nature and function of pride. Current directions in psychological science, 16(3), 147-150. https://doi.org/10.1111/j.1467-8721.2007.00493.x

Tracy, J. L. , \& Robins, R. W. (2004). Putting the self into self-conscious emotions: A theoretical model. Psychological Inquiry , 15, 103-125. https://doi.org/10.1207/s15327965pli1502_01

Tracy, J. L., \& Robins, R. W. (2008). The nonverbal expression of pride: evidence for crosscultural recognition. Journal of personality and social psychology, 94(3), 516.

Tracy, J. L., Shariff, A. F., \& Cheng, J. T. (2010). A naturalist's view of pride. Emotion Review, 2(2), 163-177. https://doi.org/10.1177/1754073909354627

Tsang, J. A. (2006). Gratitude and prosocial behaviour: An experimental test of gratitude. Cognition \& Emotion , $20,138-148$. https://doi.org/10.1080/02699930500172341

Uz, I. (2015). The index of cultural tightness and looseness among 68 countries. Journal of Cross-Cultural Psychology, 46(3), 319-335. https://doi.org/10.1177\%2F0022022114563611

Valdesolo, P., Shtulman, A., \& Baron, A. S. (2017). Science is awe-some: The emotional antecedents of science learning. Emotion Review, 9(3), 215-221. https://doi.org/10.1177/1754073916673212

Vaish, V. (2007). Globalisation of language and culture in Singapore. International Journal of Multilingualism, 4(3), 217-233. https://doi.org/10.2167/ijm073.0

Weidman, A. C., \& Tracy, J. L. (2020). Picking up good vibrations: Uncovering the content of distinct positive emotion subjective experience. Emotion, 20(8), 13111331. https://doi.org/10.1037/emo0000677

Weiner, B. (1985). An attributional theory of achievement motivation and emotion. Psychological Review , 92 , 548-573. https://doi.org/10.1037/0033295X.92.4.548 
Williams, L. A., \& DeSteno, D. (2009). Pride: Adaptive social emotion or seventh sin?. Psychological Science, 20(3), 284-288. https://doi.org/10.1111/j.14679280.2009.02292.x

Yeoh, B. S. (2004). Cosmopolitanism and its exclusions in Singapore. Urban Studies, 41(12), 2431-2445. https://doi.org/10.1080\%2F00420980412331297618

Yih, J., Kirby, L. D., \& Smith, C. A. (2020). Profiles of appraisal, motivation, and coping for positive emotions. Cognition and Emotion, 34(3), 481-497.

https://doi.org/10.1080/02699931.2019.1646212

Yuki, M., Maddux, W. W., \& Masuda, T. (2007). Are the windows to the soul the same in the East and West? Cultural differences in using the eyes and mouth as cues to recognize emotions in Japan and the United States. Journal of Experimental Social Psychology, 43(2), 303-311. https://doi.org/10.1016/j.jesp.2006.02.004 